\author{
GEORGE L. PERRY* \\ Brookings Institution
}

\title{
Unemployment Flows in the U.S. Labor Market
}

UNEMPLOYMENT IS ALWAYS NEAR the forefront of economic policy issues, but what is perceived as the chief unemployment problem keeps changing. For most of the decade after 1956, excessive cyclical unemployment was the chief policy problem. Its solution lay in restoring full employment by expanding aggregate demand. As this purpose was achieved, inflation emerged and unemployment as a policy problem took on two new dimensions. One was how to reconcile full employment with reasonable price stability. The other was how to reduce the excessive unemployment that some groups of workers still suffered and that became increasingly apparent as unemployment elsewhere became negligible. The new problems were harder ones. They stimulated new research and innovative policy proposals. Now, in the early 1970s, cyclical unemployment has reemerged before any permanent solutions to the other problems have been found. And the unemployment issue has taken on still another dimension: uncertainty about what portion of unemployment is "purely cyclical" and what the aggregate "full unemployment" target should be. The old 4 percent goal brings more inflationary pressures than the nation cares to tolerate yet still leaves many groups of workers, particularly blacks and younger workers, suffering excessive unemployment and poor job opportunities.

Today, fixing an unemployment target must take account of all three

* I want to thank Nancy Hwang and Herbert F. Lowrey, Jr., for their research assistance in the preparation of this paper. 
aspects of the protlem. How low we can push the global unemployment rate will depend on how well we can control inflation without resorting to slack markets and on how successfully we can cope with structural unemployment and reduce unemployment disparities among the various groups in the labor force.

Research efforts have been useful in defining today's unemployment problem as well as in suggesting some remedies. Efforts have focused on understanding the unemployment-inflation link, diagnosing areas of pathologically high unemployment, and devising specific labor market and manpower programs for reducing pockets of high unemployment. Disaggregating information about the labor market has helped in identifying significant changes in the composition of unemployment and in the unemployment experience of various parts of the work force. And some new insights on the kinds of labor market experience that lie behind the unemployment statistics have come from recent theoretical models, particularly those that view unemployment in the context of job search by workers flowing through the labor market. ${ }^{1}$

The present paper offers a disaggregated analysis of unemployment flows. The first part develops a model for analyzing the experience of various demographic groups in terms of the probabilities that govern the flow of workers into and out of unemployment. With these probabilities, the frequency with which unemployment spells are experienced by the average worker and the average duration of each spell can be calculated for any unemployment rate. These characteristics are used to compare the unemployment experience of demographic groups, to analyze cyclical variations in unemployment, and to examine the change in the unemployment experience of the groups since the 1950s. While all this answers some questions, it raises a number of others. In particular, it shows that frequent transitions into and out of unemployment characterize the experience of labor force

1. Specific papers have overlapped in their focus on the several parts of the problem just described. General references would include Charles C. Holt, C. Duncan MacRae, Stuart O. Schweitzer, and Ralph E. Smith, "Manpower Programs To Reduce Inflation and Unemployment: Manpower Lyrics for Macro Music," Institute Paper 350-28 (Urban Institute, 1971; processed); Charles C. Holt, "Job Search, Phillips' Wage Relation, and Union Influence: Theory and Evidence," in Edmund S. Phelps and others, Microeconomic Foundations of Employment and Inflation Theory (Norton, 1970); Robert E. Hall, "Why Is the Unemployment Rate So High at Full Employment?" Brookings Papers on Economic Activity (3:1970), pp. 369-402; Peter B. Doeringer and Michael J. Piore, Internal Labor Markets and Manpower Analysis (Heath, 1971); and George L. Perry, "Changing Labor Markets and Inflation," Brookings Papers on Economic Activity (3:1970), pp. 411-41. 
groups that typically experience high unemployment rates. The second part of the paper uses additional information on flows through the labor market to shed some light on the nature of these transitions.

\section{A Model of Unemployment Probabilities}

The pool of the unemployed changes continually. Each week a large number of workers, on the order of magnitude of one-fifth of the total number of unemployed, enter unemployment, and a comparable number leave it. Total unemployment rises or falls depending on whether more workers enter or leave. These flows, in turn, are governed by unemployment probabilities.

In any week, every member of the work force faces some probability of being unemployed the next. This probability depends both on his individual circumstances and on the overall state of the labor market. On average, the probability is higher if he is already unemployed rather than working; if he is young rather than adult; if he is black rather than white. It may also vary for less obvious reasons, such as how long he has already been unemployed. And whatever his individual circumstances, the probability will be higher if the overall labor market is slack rather than tight.

\section{FLOWS OUT OF UNEMPLOYMENT}

Unemployed workers are looking for jobs. They can leave unemployment either by getting a job or by leaving the work force. In the process of job search, each unemployed person can be conceived of as having a lottery ticket. If his number comes up, he gets a job. If not, and if he does not quit the lottery and leave the labor force, he continues unemployed another week. The probability that he continues unemployed an additional week is known as the continuation rate. The number of unemployed, multiplied by one minus the continuation rate, equals the flow out of unemployment each week.

\section{FLOWS INTO UNEMPLOYMENT}

The unemployed are not the only workers in the market for jobs. In manufacturing alone, job accessions are about 4 to 5 percent of total employment each month. If manufacturing is typical of the economy as a 
whole, this means accessions in one month are approximately equal to the number of unemployed. As the flow into employment from unemployment is not nearly that great (many of those leaving unemployment do not find jobs but leave the work force), the number of workers looking for new jobs is substantial. It consists of persons about to enter the labor force, and of workers about to leave one job to look for another, either at their own initiative (quitting) or at their employer's (layoff or firing).

These additional job seekers can be conceived of as holding lottery tickets just as the unemployed do. These tickets define the probability that, when they make the transition into the labor force or out of their present jobs, their numbers come up and they have new jobs. If their numbers do not come up, they become this week's newly unemployed. The size of this flow into unemployment, determined by the number of persons in this pool seeking jobs multiplied by their average probability of not finding them, thus defines the number of new spells of unemployment experienced in the economy. This conceptualization of the process by which people become unemployed must be understood in terms of average probabilities for persons in quite different individual circumstances. Many individuals enter the work force or leave their present jobs only to accept a job offer. For these members of the pool of job seekers, the probability of having a new job is 1.0 by definition. But if they are included with all entrants and job changers, there is an average probability that someone in these categories will become unemployed. Among job changers, it is commonplace to search for a job while holding one, as a person who had been given notice of an impending layoff or who was dissatisfied with his job might do. Probabilities would then attach to his chances of locating a job over some variable period when he was looking while still working. For any weekly probability of finding a job, the chances that such a worker ends up unemployed when he leaves his present job-the thing that is in principle observable-will depend on how many weeks he looked before leaving.

The size and composition of this mixed pool of job seekers is not known, so that direct estimates of the probabilities just described cannot be made. But this model of the process is useful in explaining variations in the number of unemployment spells experienced. For unless allowance is made for variations in the probability that these job seekers find jobs rather than becoming unemployed, all variations in the number of unemployment spells occurring in the economy would have to arise from proportional variations in the number of these job seekers. I do not want to assume this; and at 
least for cyclical variations in unemployment, empirical evidence presented below indicates that this cannot be so. But since this pool of job seekers cannot be measured, the determinants of flows into unemployment cannot be estimated directly. Instead, flows out of unemployment-the oppositeare estimated, using an empirical model built around the determinants of unemployment continuation rates. And from these, other characteristics of unemployment experience, including the number of unemployment spells experienced, can be inferred.

In doing this, the present paper will build on an important analysis of continuation rates published by Kaitz. ${ }^{2}$ In it he develops the relations among continuation rates, unemployment rates, and the duration and frequency of unemployment spells. The estimates of continuation rates generated in the present model will be used to extend some of Kaitz's analysis of these characteristics of unemployment.

\section{WEEKLY FLOWS AND MONTHLY DATA}

The first object is to devise a model for calculating weekly continuation rates from available monthly data. Kaitz's analysis offers one important observation on continuation rates that must be allowed for in such calculations. He has shown that continuation rates using aggregate data are higher for those who have already experienced long unemployment spells than for those with shorter ones. As he has noted, this can be true for either of two reasons: First, the probability that any individual continues unemployed another week can rise with the number of weeks he has already been unemployed. An individual's lottery ticket gets less valuable the longer he holds it, possibly because he explores quickly the most promising chances of getting a job. Second, the lottery ticket, or expected continuation rate, can be constant throughout an individual's spell, but the flow into unemployment contains individuals with expected continuation rates that differ widely. On average, those with better lottery tickets (low continuation rates) will leave unemployment earlier than the others. Those remaining unemployed will have worse lottery tickets, on average, than those who left. Experimenting with data disaggregated by detailed demographic groups did not turn up enough variation in continuation rates to justify the second as-

2. Hyman B. Kaitz, "Analyzing the Length of Spells of Unemployment," Monthly Labor Review. Vol. 93 (November 1970), pp. 11-20. 
sumption for this study; so variation of the first type must be allowed for in the model.

Disaggregated monthly data are available on the number of workers unemployed less than five weeks and five weeks or more. ${ }^{3}$ From these, it is possible to infer enough about weekly continuation rates to derive the characteristics of unemployment required for this analysis. ${ }^{4}$ Although continuation rates apparently change throughout the duration of an unemployment spell, it is sufficient to distinguish between an average continuation rate applicable to each of the first four weeks of an unemployment spell and an average rate applicable to the remaining weeks of a spell. Even with this simplification, the relationships involved are complex. The following definitions are needed in order to explain them:

$$
\begin{aligned}
N= & \text { number newly unemployed each week } \\
p= & \text { weekly continuation rate for those unemployed less than five } \\
& \text { weeks } \\
q= & \text { weekly continuation rate for those unemployed five weeks or } \\
& \text { more } \\
U= & \text { total unemployment } \\
U^{*}= & \text { number unemployed less than five weeks } \\
U^{* *}= & \text { number unemployed five weeks or more. }
\end{aligned}
$$

With these variables, two kinds of subscripts are needed, reflecting the fact that unemployment surveys are taken monthly: The subscript 1 will refer to any week in the month since the last unemployment survey, the subscript 0 to any week in the previous month. These 0 and 1 subscripts will be used with the basic flow parameters, $p, q$, and $N$. The subscript $t$ will refer to the week of the present monthly survey; the subscript $t-1$ to the previous week. These $t$ and $t-1$ subscripts will be used with the basic stock measures, $U, U^{*}$, and $U^{* *}$.

Any change in the flow parameters, $p, q$, and $N$, is assumed to occur at the start of a (survey) month and then to remain unchanged until the next

3. As the week is the basic unit of measure in this survey, less than five weeks is equivalent to one to four weeks.

4. Smith and Holt have used these data for a similar purpose; they did not try to infer weekly continuation rates, however, but worked directly with the monthly changes instead. See Ralph E. Smith and Charles C. Holt, "A Job Search-Turnover Analysis of the Black-White Unemployment Ratio," in Gerald G. Somers (ed.), Proceedings of the Twenty-third Annual Winter Meeting, 1970, Industrial Relations Research Association Series (IRRA, 1971). 
survey, a month later. By definition, all of the newly unemployed, $N$, remain jobless in the initial week of the month. The second week a fraction, $p$, of them continue unemployed; the third week the fraction is $p^{2}$, and the fourth, $p^{3}$. Since each week there are $N$ newly unemployed, the number unemployed less than five weeks at the end of the month will include workers in their first, second, third, and fourth weeks of unemployment, with the number of each determined by the continuation rate analysis just described. Thus, in the week of a new unemployment survey, the number unemployed less than five weeks, $U^{*}$, is

$$
U_{t}^{*}=N_{1}\left(1+p_{1}+p_{1}^{2}+p_{1}^{3}\right) .
$$

In the previous week, for which there is no survey observation, the equivalent relation is

$$
U_{t-1}^{*}=N_{1}\left(1+p_{1}+p_{1}^{2}\right)+N_{0} p_{0} p_{1}^{2},
$$

since those in their fourth week of unemployment at time $t-1$ originally numbered $N_{0}$ and had continuation rates $p_{0}$ between their first and second week of unemployment.

The next requirement is for an expression for the number of persons unemployed five weeks or more, $U^{* *}$. In week $t$, these will consist of those who were unemployed four weeks or more last week and who continued unemployed one more week. As just explained, the number unemployed four weeks as of last week is $N_{0} p_{0} p_{1}^{2}$; while the number with longer spells last week is $U_{t-1}^{* *}$. Since $q_{1}$ is the continuation rate in week $t$ for these workers,

$$
U_{t}^{* *}=q_{1}\left(N_{0} p_{0} p_{1}^{2}+U_{t-1}^{* *}\right)
$$

Solving (3) for $U_{t-1}^{* *}$ and adding it to $U_{t-1}^{*}$ given by equation (2) yields

$$
U_{t-1}=N_{1}\left(1+p_{1}+p_{1}^{2}\right)+\frac{1}{q_{1}} U_{t}^{* *}
$$

and solving (1) for $N_{1}$ and substituting into (4) gives

$$
U_{t-1}=\left(\frac{1+p_{1}+p_{1}^{2}}{1+p_{1}+p_{1}^{2}+p_{1}^{3}}\right) U_{t}^{*}+\frac{1}{q_{1}} U_{t}^{* *} .
$$

Finally, the two weekly continuation rates, $p$ and $q$, must be related; to do so, the analysis sets $p$ as the basic continuation rate parameter for the model and assumes that $q$ is proportional to $p$ :

$$
p=m q,
$$


where $m$ is the proportionality factor, which Kaitz's data suggest is less than 1.0. Equation (6) is assumed to hold at all times and at all levels of unemployment. It makes explicit the viewpoint of the model that unemployment flows throughout are governed by weekly probabilities that vary with labor market conditions. Since $p$ and $q$ are both basic weekly probabilities, the assumption that they move proportionally seems tenable.

Substituting the condition of equation (6) into equation (5) yields a fourth-order equation in the continuation parameter $p$ :

$$
-m U_{t}^{* *}+\left(p+p^{2}+p^{3}\right)\left(U_{t-1}-U_{t}^{*}-m U_{t}^{* *}\right)+p^{4} U_{t-1}=0 .
$$

The value of $U_{t-1}$, unemployment a week before each month's survey, is approximated by assuming linear unemployment change between any two months. For empirical work, a trial-and-error procedure was used to locate the appropriate value of $m$. For the year 1969, Kaitz presented an estimate of the economy-wide weekly continuation rate for the first month of unemployment. In the present model, $m=0.84$ produced values of $p$ for each demographic group that averaged to Kaitz's economy-wide estimate in the year 1969. Given this value of $m$ and monthly data on unemployment, the roots of equation (7) were found for each month and the relevant root chosen as the value of $p$ each month. This was done for each of eight demographic groups of the labor force. Thus from the available monthly data on the stocks $U, U^{*}$, and $U^{* *}$, this procedure generated monthly estimates of the continuation rate $p$ (and hence of $q$ ) for each of the demographic groups. In the empirical model presented below, these constructed data on $p$ are treated as the basic measure of labor market conditions confronting job seekers. The object is to explain them.

\section{EQUILIBRIUM PROPERTIES: SPELLS AND DURATION}

Before turning to empirical estimates of the determinants of $p$, the equilibrium properties of the present flow model can be derived. In equilibrium, the number of workers entering and leaving unemployment will be equal and the numbers unemployed more and less than five weeks will be constant, so that

$$
N=(1-p) U^{*}+\left(1-\frac{p}{m}\right) U^{* *} ;
$$

the first and second expressions on the right-hand side give the number of workers leaving unemployment from the group with less than five weeks 
unemployment and from the group with five weeks or more, respectively. On the basis of the identity $U=U^{*}+U^{* *}$, and equation (1), which relates the number of workers with less than five weeks of unemployment to the weekly flow into unemployment, equation (8) becomes

$$
N=\frac{U(m-p)}{m-p(1-m)\left(1+p+p^{2}+p^{3}\right)} ;
$$

or as fractions of the work force $L$, where $n=N / L$ and the group unemployment rate $u=U / L$,

$$
n=\frac{u(m-p)}{m-p(1-m)\left(1+p+p^{2}+p^{3}\right)} .
$$

In equilibrium, the duration of an average spell of unemployment measured in weeks, $D$, is simply total unemployment divided by the number of new unemployment spells per week:

$$
D=\frac{U}{N}=\frac{u}{n}
$$

so, in terms of the continuation rate parameter, $p$,

$$
D=\frac{m-p(1-m)\left(1+p+p^{2}+p^{3}\right)}{m-p} .
$$

If continuation rates were constant throughout each spell, $m$ would equal 1.0 and the expression for duration would simplify to

$$
D=\frac{1}{1-p} \text {. }
$$

It is worth noting the conceptual difference between the average duration of a spell of unemployment as defined here and the average duration of unemployment as it is defined in published unemployment statistics. The concept used here refers to the average length of completed spells. It measures how long a person entering unemployment can expect to remain unemployed. The published data measure how long the average person currently unemployed has been unemployed. It can be shown that, if continuation rates are constant throughout a spell, these two measures will be equal in equilibrium. If continuation rates vary systematically throughout the length of a spell, the two measures will differ, even in equilibrium.

Estimating and comparing these equilibrium characteristics of unemployment experience for different labor force groups at different times is one primary aim of the empirical analysis of this model. Since the flow 
probabilities, reflected in the continuation parameter, $p$, characterize the job-hunting experience actually confronting individual workers looking for jobs, estimation is done on explaining $p$; other characteristics of unemployment are calculated from that estimate using the relations just derived.

\section{Empirical Estimates}

The expectation is that $p$ will vary according to the state of the labor market confronting an unemployed worker. The number of job opportunities, represented by job vacancies, as well as the competition for these jobs, represented by unemployment, could be expected to govern the weekly probability that an unemployed person gets a job. Together with the factors that move him to leave the work force rather than continue looking for work, these labor market conditions would determine the continuation rate, $p$. The decision to leave the work force also could be related to labor market conditions, perhaps to the length of time already spent unemployed, or to $p$ itself.

Here these labor market conditions that determine $p$ are approximated simply by the unemployment rate and changes in that rate. Since vacancies and unemployment are closely related cyclically, there is reason as well as considerable precedent for using unemployment as a proxy for the two. ${ }^{5}$ In addition, ultimate interest lies in the relation between unemployment and continuation probabilities, so the direct use of unemployment rates as the main explanatory variable can be justified as the most direct way of estimating that reduced form relationship.

The change in unemployment, which is included as an additional explanatory variable, must capture a rather complicated dynamic relation between $p$ and unemployment. There are two sides to this relation. First, changes in $p$ act on $u$ in a complex way that does not work itself out in one period. If $p$ rose to a new level one month and then stayed there, $u$ would keep changing for some time afterward even if the number of new spells, $N$, did not change. A change term is needed to allow for this lag in the relation of $p$ back onto $u$. Second, a change term is needed because, when labor mar-

5. For some empirical work on search models that develops the relationship to vacancies more explicitly, see C. Duncan MacRae and Stuart O. Schweitzer, "The Relation between Vacancies and Unemployment," Urban Institute Working Paper 350-42 (November 1972). 
kets change, the timing of the response of $N$ and of $p$ to this change may not be the same. Thus, if unemployment starts to rise 0.1 point a month, the initial impacts on $p$ and $N$ may be different from the eventual impacts. This possibility also requires a change term in the equation relating $p$ to unemployment. These dynamic complications will be examined again when the empirical results are presented.

The other explanatory variable used is a time trend. Relative unemployment rates among demographic groups have changed significantly during the postwar period, and such changes may have important implications for the meaning of the overall unemployment rate in terms of labor market tightness and inflationary pressures originating in the labor market. ${ }^{6}$ The time trends will determine how these relative unemployment changes break down in terms of changes in the average duration and in frequency of spells of unemployment.

\section{THE FORM OF THE RELATION}

Empirical estimates of the continuation rate parameter, $p$, were made experimentally with several alternative forms of the relationship between it and unemployment. It was important to try alternatives because the cyclical relationship between unemployment, on the one hand, and its division into the duration and frequency of spells, on the other, is sensitive to the form chosen. Each alternative was tested in an estimating equation that included changes in unemployment and a time trend as additional explanatory variables. The alternatives were then compared by the ability of each equation to predict $p$ itself and $1 /(1-p)$, which is the algebraic form of $p$ that comes nearest to measuring the average duration of unemployment spells in equilibrium. Table 1 summarizes these comparisons. Seven alternatives were compared for the oldest male group and the four best of these were further compared for three other labor force groups-25- to 44-year-old men and the youngest men and women.

The two logarithmic forms of the equations dominated all the others for all the groups tested. Where there was a noticeable difference in predictive ability between the two logarithmic forms, the comparisons favored equation $(\mathrm{G})$, which uses the probability of leaving unemployment, $1-p$, in the dependent variable. This form of the equation was, therefore, chosen for

6. Perry, "Changing Labor Markets and Inflation." 


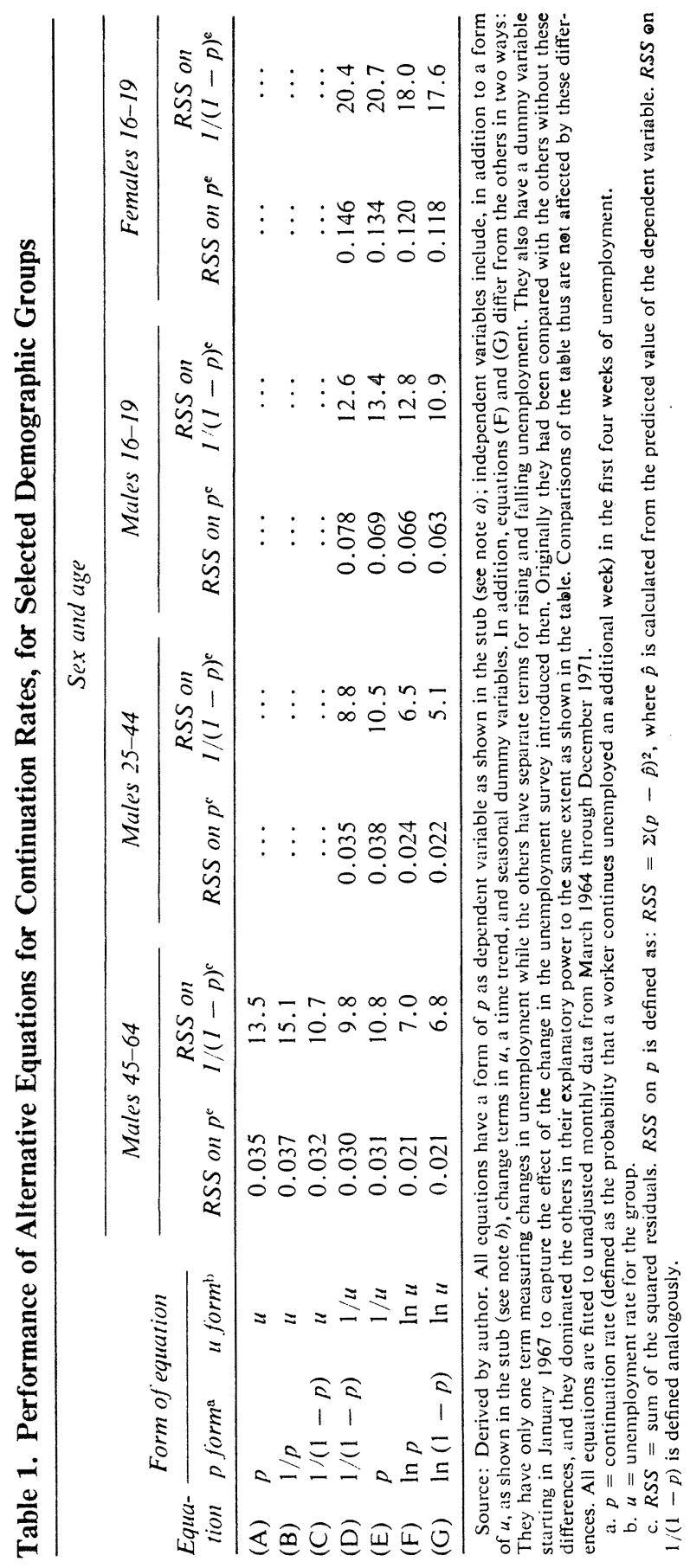


subsequent analysis. It indicates that the probability of leaving unemployment has an approximately constant elasticity with respect to unemployment rates.

One point is worth noting about the change term in the equation. Initially, separate change terms were used to distinguish between months when unemployment was rising and months when it was falling. Coefficient estimates on these separate terms were virtually identical for seven of the eight demographic groups and less than one standard error apart for the eighth. This indicated that there was no asymmetry in the response to rising or falling unemployment and the equations were rerun with only a single change term covering both conditions.

The final equation is

$$
\begin{aligned}
\ln \left(1-p_{t}\right)=a_{0}+a_{1} \ln u_{t}+a_{2} \ln ( & \left.\frac{u_{t}}{u_{t-1}}\right)+a_{3} T+a_{4} S \\
& + \text { (seasonal dummy variables) }
\end{aligned}
$$

where

$p$ is the continuation rate in the first four weeks of unemployment

$u$ is the unemployment rate for the group

$T$ is a monthly time trend equal to 1 in January 1954

$S$ is a dummy variable equal to 1 starting January 1967 (when the survey definition of unemployment was changed), and 0 before that.

Estimates for equation (12) are shown in Table 2 for eight separate agesex breakdowns of the total labor force. Estimates for workers 65 years old and over were erratic and are not used. The regressions were fitted to monthly data for the period March 1954 through December 1971.

\section{Cyclical Comparisons}

Table 3 compares the frequency and duration of unemployment spells experienced at different equilibrium levels of unemployment for each of the age-sex groups. The table is based on the equation estimates of Table 2. All calculations are for the 1972 economy. For each demographic group, the unemployment rate associated with each aggregate unemployment rate is estimated using relations established in a previous paper. ${ }^{7}$ The equations of

7. George L. Perry, "Labor Force Structure, Potential Output, and Productivity," Brookings Papers on Economic Activity (3:1971), pp. 533-65. 
Table 2. Regression Estimates for Continuation Rates in the First Four Weeks of Unemployment, by Sex and Age

\begin{tabular}{|c|c|c|c|c|c|c|c|}
\hline \multirow{2}{*}{$\begin{array}{l}\text { Sex } \\
\text { and } \\
\text { age }\end{array}$} & \multicolumn{5}{|c|}{ Regression coefficients $\mathrm{a}^{\mathrm{a}}$} & \multirow[b]{2}{*}{$\bar{R}^{2}$} & \multirow{2}{*}{$\begin{array}{l}\text { Durbin- } \\
\text { Watson } \\
\text { statistic }\end{array}$} \\
\hline & $a_{0}$ & $a_{1}$ & $a_{2}$ & $a_{3}$ & $a_{4}$ & & \\
\hline \multicolumn{8}{|l|}{ Male } \\
\hline $16-19$ & $\begin{array}{l}-1.932 \\
(-34.6)\end{array}$ & $\begin{array}{l}-0.270 \\
(-10.2)\end{array}$ & $\begin{array}{l}-0.701 \\
(-16.8)\end{array}$ & $\begin{array}{r}0.00091 \\
\quad(7.8)\end{array}$ & $\begin{array}{r}-0.0109 \\
(-0.7)\end{array}$ & 0.88 & 1.53 \\
\hline $20-24$ & $\begin{array}{l}-1.954 \\
(-59.9)\end{array}$ & $\begin{array}{l}-0.237 \\
(-18.0)\end{array}$ & $\begin{array}{l}-0.668 \\
(-19.9)\end{array}$ & $\begin{array}{r}0.00024 \\
(2.4)\end{array}$ & $\begin{array}{r}0.0108 \\
(0.8)\end{array}$ & 0.89 & 1.63 \\
\hline $25-44$ & $\begin{array}{l}-2.020 \\
(-65.9)\end{array}$ & $\begin{array}{l}-0.189 \\
(-20.5)\end{array}$ & $\begin{array}{l}-0.627 \\
(-17.5)\end{array}$ & $\begin{array}{r}-0.00004 \\
(-0.5)\end{array}$ & $\begin{array}{r}-0.0406 \\
(-3.9)\end{array}$ & 0.91 & 1.45 \\
\hline $45-64$ & $\begin{array}{l}-1.912 \\
(-49.7)\end{array}$ & $\begin{array}{l}-0.140 \\
(-11.7)\end{array}$ & $\begin{array}{l}-0.701 \\
(-17.7)\end{array}$ & $\begin{array}{r}-0.00019 \\
(-2.4)\end{array}$ & $\begin{array}{r}-0.0229 \\
(-2.0)\end{array}$ & 0.86 & 1.43 \\
\hline \multicolumn{8}{|l|}{ Female } \\
\hline $16-19$ & $\begin{array}{l}-1.625 \\
(-16.1)\end{array}$ & $\begin{array}{c}-0.162 \\
(-3.7)\end{array}$ & $\begin{array}{l}-0.687 \\
(-13.0)\end{array}$ & $\begin{array}{r}0.00058 \\
(2.8)\end{array}$ & $\begin{array}{r}-0.0067 \\
(-0.3)\end{array}$ & 0.81 & 1.48 \\
\hline $20-24$ & $\begin{array}{l}-2.013 \\
(-26.1)\end{array}$ & $\begin{array}{c}-0.258 \\
(-9.1)\end{array}$ & $\begin{array}{l}-0.735 \\
(-18.2)\end{array}$ & $\begin{array}{r}0.00083 \\
(6.2)\end{array}$ & $\begin{array}{r}-0.02910 \\
(-1.6)\end{array}$ & 0.81 & 1.48 \\
\hline $25-44$ & $\begin{array}{l}-2.045 \\
(-32.7)\end{array}$ & $\begin{array}{c}0.226 \\
(-10.8)\end{array}$ & $\begin{array}{l}-0.665 \\
(-13.7)\end{array}$ & $\begin{array}{r}0.00041 \\
(4.4)\end{array}$ & $\begin{array}{r}0.0199 \\
(1.5)\end{array}$ & 0.79 & 1.82 \\
\hline $45-64$ & $\begin{array}{l}-2.049 \\
(-33.5)\end{array}$ & $\begin{array}{l}-0.198 \\
(-10.4)\end{array}$ & $\begin{array}{l}-0.675 \\
(-20.0)\end{array}$ & $\begin{array}{r}-0.00010 \\
(-1.0)\end{array}$ & $\begin{array}{r}0.0352 \\
(2.7)\end{array}$ & 0.84 & 1.33 \\
\hline
\end{tabular}

a. The regression equation for each age-sex group is $\ln \left(1-p_{t}\right)=a_{0}+a_{1} \ln u_{t}+a_{2} \ln \left(\frac{u_{t}}{u_{t-1}}\right)+a_{3} T+a_{4} S+$ (seasonal dummy variables),

where $p$ is the continuation rate in the first four weeks of unemployment $u$ is the unemployment rate for the group

$T$ is the monthly time trend equal to 1 in January 1954

$S$ is a dummy variable equal to 1 starting January 1967 (when the survey definition of unemployment was changed), and 0 before that.

The period of fit is March 1954 through December 1971. The numbers in parentheses are $t$-statistics.

Table 2 are then used to predict $p$ for each level of unemployment with the time trend evaluated for 1972. These values of $p$ are then used to calculate the average duration of unemployment spells using the equilibrium relationship of equation (11). The frequency of unemployment spells are then calculated using equation (10).

Values of $p$ vary by age groups, the aggregate unemployment rate, and, for some groups, the period of time. Average values of $p$ over the whole data period ranged from 0.705 for teenage girls to 0.765 for the oldest male groups. Since these are weekly probabilities of continuing unemployed, the difference in the probability of being unemployed after five weeks is the 
Table 3. Cyclical Variation in Unemployment Spells at Various Unemployment Levels, by Sex and Age, 1972 Economy

\begin{tabular}{|c|c|c|c|c|c|c|}
\hline \multirow{3}{*}{$\begin{array}{c}\text { Sex and age group, } \\
\text { and aggregate } \\
\text { unemployment } \\
\text { rate } \\
U \\
\text { (percent) }\end{array}$} & \multirow{3}{*}{$\begin{array}{l}\text { Group un- } \\
\text { employment } \\
\text { rate } \\
u \\
\text { (percent) }\end{array}$} & \multicolumn{2}{|c|}{ Unemployment spells } & \multirow{2}{*}{\multicolumn{3}{|c|}{$\begin{array}{c}\text { Percentage change from } \\
\text { one unemployment level } \\
\text { to the next } t^{\mathrm{a}}\end{array}$}} \\
\hline & & \multirow{2}{*}{$\begin{array}{c}\text { Average } \\
\text { length } \\
D \\
\text { (weeks) }\end{array}$} & \multirow{2}{*}{$\begin{array}{c}\text { Number } \\
\text { per year } \\
\text { per worker } \\
n\end{array}$} & & & \\
\hline & & & & $u$ & $D$ & $n$ \\
\hline \multicolumn{7}{|l|}{ Males } \\
\hline $16-19: 3.0$ & 8.9 & 3.3 & 1.41 & $\ldots$ & $\ldots$ & $\ldots$ \\
\hline 4.0 & 11.5 & 3.7 & 1.63 & 29 & 11 & 16 \\
\hline 5.0 & 14.0 & 4.0 & 1.82 & 22 & 9 & 12 \\
\hline 6.0 & 16.6 & 4.3 & 1.99 & 18 & 8 & 9 \\
\hline 7.0 & 19.1 & 4.7 & 2.14 & 15 & 8 & 7 \\
\hline $20-24: 3.0$ & 5.6 & 4.0 & 0.73 & $\ldots$ & $\ldots$ & $\ldots$ \\
\hline 4.0 & 7.0 & 4.4 & 0.83 & 24 & 10 & 13 \\
\hline 5.0 & 8.4 & 4.8 & 0.91 & 20 & 8 & 10 \\
\hline 6.0 & 9.8 & 5.1 & 0.99 & 16 & 8 & 8 \\
\hline 7.0 & 11.1 & 5.5 & 1.05 & 14 & 7 & 7 \\
\hline $25-44: 3.0$ & 1.3 & 4.3 & 0.16 & $\ldots$ & $\ldots$ & \\
\hline 4.0 & 2.1 & 5.1 & 0.21 & 62 & 19 & 35 \\
\hline 5.0 & 2.9 & 5.8 & 0.26 & 38 & 15 & 20 \\
\hline 6.0 & 3.7 & 6.6 & 0.29 & 28 & 12 & 14 \\
\hline 7.0 & 4.5 & 7.3 & 0.32 & 22 & 11 & 10 \\
\hline $45-64: 3.0$ & 1.1 & 5.2 & 0.11 & & & \\
\hline 4.0 & 1.8 & 6.1 & 0.15 & 62 & 17 & 38 \\
\hline 5.0 & 2.5 & 6.9 & 0.19 & 38 & 13 & 23 \\
\hline 6.0 & 3.2 & 7.6 & 0.22 & 27 & 10 & 16 \\
\hline 7.0 & 3.9 & 8.3 & 0.24 & 22 & 9 & 12 \\
\hline \multicolumn{7}{|l|}{ Females } \\
\hline $16-19: 3.0$ & 8.4 & 3.4 & 1.30 & & 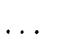 & \\
\hline 4.0 & 11.4 & 3.6 & 1.63 & 35 & 8 & 25 \\
\hline 5.0 & 14.4 & 3.9 & 1.94 & 26 & 6 & 19 \\
\hline 6.0 & 17.4 & 4.1 & 2.22 & 21 & 5 & 15 \\
\hline 7.0 & 20.3 & 4.3 & 2.48 & 17 & 5 & 12 \\
\hline $20-24: 3.0$ & 4.4 & 3.2 & 0.73 & & $\ldots$ & \\
\hline 4.0 & 6.1 & 3.6 & 0.89 & 39 & 13 & 23 \\
\hline 5.0 & 7.9 & 4.0 & 1.03 & 28 & 11 & 16 \\
\hline 6.0 & 9.6 & 4.3 & 1.15 & 22 & 9 & 12 \\
\hline 7.0 & 11.4 & 4.7 & 1.26 & 18 & 8 & 9 \\
\hline $25-44: 3.0$ & 3.6 & 3.8 & 0.49 & & & \\
\hline 4.0 & 4.3 & 4.1 & 0.55 & 22 & 8 & 13 \\
\hline 5.0 & 5.1 & 4.4 & 0.60 & 18 & 7 & 10 \\
\hline 6.0 & 5.9 & 4.7 & 0.65 & 15 & 6 & 8 \\
\hline 7.0 & 6.6 & 4.9 & 0.70 & 13 & 6 & 7 \\
\hline $45-64: 3.0$ & 2.3 & 4.6 & 0.26 & . & 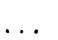 & - \\
\hline 4.0 & 2.8 & 5.0 & 0.29 & 22 & 8 & 13 \\
\hline 5.0 & 3.3 & 5.4 & 0.32 & 17 & 7 & 10 \\
\hline 6.0 & 3.8 & 5.7 & 0.35 & 15 & 7 & 8 \\
\hline 7.0 & 4.3 & 6.1 & 0.37 & 13 & 6 & 7 \\
\hline
\end{tabular}

Source: Calculated from equation estimates in Table 2 using the equilibrium relations of equations (10) and (11) in the text.

a. The percentage changes are computed from unrounded data. 
difference in these probabilities to the fifth power, or 0.17 for the teenage girls compared with 0.26 for the older men.

\section{DEMOGRAPHIC DIFFERENCES}

Important differences of duration and frequency of spells characterize the several demographic groups. For instance, at a 5 percent aggregate unemployment rate, teenagers of either sex experience an average of nearly two unemployment spells a year while older men experience an average of only one spell every four to five years. Between these extremes, the frequency of spells declines steadily with the age of workers of either sex group.

The average duration of spells varies in the opposite direction, although not nearly so dramatically. At a 5 percent aggregate unemployment rate, spells average around four weeks for teenagers, and nearly seven weeks for men in the oldest groups.

In contrast with these striking differences in the frequency and duration of spells among the demographic groups, the cyclical patterns of frequency and duration within each group are very much the same for all groups. In all of them, the elasticity of duration with respect to unemployment rises slightly with higher unemployment rates. What differences there are in this elasticity among groups are not great, and would have been hard to predict: Changes in duration account for a smaller than average part of unemployment changes both for the oldest men and the youngest women. With a few minor exceptions, which appear at the highest unemployment rates, higher unemployment is accounted for more by increased frequency of spells than by lengthened duration of spells.

This cyclical pattern differs substantially from the one reported by Kaitz. ${ }^{8}$ For the whole work force, he estimated that the elasticity of duration with respect to unemployment rose sharply with the unemployment rate. Higher duration accounted for all the difference between a 5 and 6 percent unemployment rate and the frequency of spells actually declined as unemployment went above 5.5 percent. Only below 3.5 percent unemployment did changes in the frequency of spells account for more than half of changes in unemployment.

Only a small part of the discrepancy with Kaitz's finding can be due to disaggregation. In Table 3, the elasticity of duration to unemployment is

8. "Analyzing the Length of Spells," p. 15. 
too similar among the groups to cause any substantial mix effect in the elasticity for the aggregate. While the two studies differ in many other aspects of procedure, the differences in this cyclical analysis almost certainly arise from the forms of the equation chosen. Kaitz regresses $n / u$ against $u$, using aggregate data. In the present model, for the special case when continuation rates are constant, $n / u$ is given by equation (9) with $m=1$. Equation (A) in Table 1 is thus the closest to the one Kaitz used and it does not compare well with the others in predictive ability. The other difference that may be important is the use of the change terms in the monthly equations of this paper. Kaitz used annual data and only the unemployment level as an explanatory variable.

\section{LONG-TERM UNEMPLOYMENT}

Because the present model distinguishes the average continuation rates only between the early and the late weeks of unemployment spells, it is bound to understate the incidence of very long-term unemployment if continuation rates in fact keep rising with each additional week of unemployment. Kaitz showed that in 1969 continuation rates kept rising along with additional weeks of unemployment for as many weeks as the data permitted reasonable estimates to be made. Calculations with the predicted equilibrium values of $p$ did understate long-term unemployment as expected. But they also lent support for the estimated cyclical movement of duration of spell just discussed.

In 1969, a year when unemployment was very low and relatively stable for several quarters, 13.2 percent of the pool had been unemployed for fifteen weeks or more. In equilibrium, at the 1969 unemployment rate, the model predicted 9.2 percent for this ratio. 9 The model also predicted a rise of 86 percent in the ratio of long-term to total unemployment between equilibrium at 1969 and 1971 unemployment rates. The actual increase was 80

9. For any demographic group, the number unemployed one to fourteen weeks can be calculated from the formula,

$$
U_{1-14}=N\left(1+p+p^{2}\right)+N p^{3}\left(1+q+q^{2}+\cdots+q^{10}\right) .
$$

Total unemployment is a similar expression in which the last term is an infinite series; unemployment longer than fourteen weeks is the difference between the two. With simplification, the desired ratio becomes $(1 / D)\left(p^{3}\right)\left(q^{11} / 1-q\right)$, where $D$ is average duration as given in equation (11). The statements in the text refer to durations aggregated over all the demographic groups. 
percent. This degree of accuracy in the predicted change in long-term unemployment suggests that the allocation of unemployment changes between spells and duration shown in Table 3 is in the right range.

\section{CYCLICAL DYNAMICS}

Every equation in Table 2 shows a large coefficient on changes in unemployment. As was suggested when the estimating equation was introduced, the interpretation of these coefficients involves an examination of the way unemployment is affected by continuation rates and new spells. In general, when labor markets weaken, unemployment increases both because continuation rates rise and because the flow of new entrants into unemployment increases. The larger the response of continuation rates to unemployment, the less remains to be accounted for by changes in the frequency of spells.

No simple analytic expression can be written to describe the dynamics involved in unemployment changes, because the relation among changes in continuation rates, new spells, and unemployment is complex. One role played by the change terms is to allow for the inherent lags in the impact of $p$ on $u$, a relation with causality running from the dependent to the independent variable in the estimating equations used here.

But rough calculations suggest that the change terms are too large to play the role solely of straightening out these lags. In addition, they indicate that, compared with the change between two equilibriums, more of the initial impact of a change in labor market conditions falls on changing the probability of leaving unemployment and less on changing the number of new unemployment spells that occur.

Two explanations of this short-run response suggest themselves. In terms of employers' response, the observed pattern could reflect the fact that the first impact of a drop in the demand for labor is on hiring rather than on firing. But it may also reflect a briefly delayed response of participation rates or job quits to changing market conditions, so that individuals continue entering the market for new jobs at the same rate as they did before opportunities weakened. This second possibility is the more likely one in view of the symmetry of the response when the cycle moves the other way. It is significant that the regressions could not distinguish differences between separate change terms for rising and falling unemployment. The co- 
efficients estimated were virtually identical, so the final equations were run with only one change term measuring both increases and decreases in unemployment. This means that when unemployment starts to fall, initially the same disproportionate impact occurs on changing $p$ as occurs when unemployment rises. An explanation that rests on a sequence in which changes in hiring precede changes in firing seems less plausible, unless such a sequence develops from an aggregation over firms in different stages of their own cyclical labor demands. But it is consistent with the kind of delayed response of quits and labor force participation rates to the improving job market that could explain the cyclical response to rising unemployment. Unfortunately, the short-run dynamics involving unemployment, continuation rates, and spells is not sufficiently articulated in this model to settle these questions.

\section{Changes through Time}

The relative unemployment rates of the various demographic groups have shifted noticeably during the postwar period. In Table 4, these shifts are decomposed into the changes in duration and frequency of spells that characterize the change in unemployment experienced between 1956 and 1972. The relative unemployment rates that actually prevailed in 1956 are used for that year; for 1972, the relative rates are those that would obtain if the average rate for men 25 to 64 was at its 1956 level. ${ }^{10}$

For all groups of younger workers, 1972 unemployment rates are projected substantially higher than those in 1956. They are also projected somewhat higher for workers in the 25- to 44-year age bracket. As it turns out, a greater frequency of spells is the overwhelming reason for these shifts in unemployment rates. For teenage girls the frequency is up 70 percent, accounting for all of the increase in their unemployment rate. For the next two age brackets for women, frequency is also up substantially, and here also it is up by more than unemployment. Greater frequency is also the dominant cause of higher unemployment for men under age 25 . Changes in the average duration of unemployment spells are not substantial for any

10. See Perry, "Labor Force Structure." 


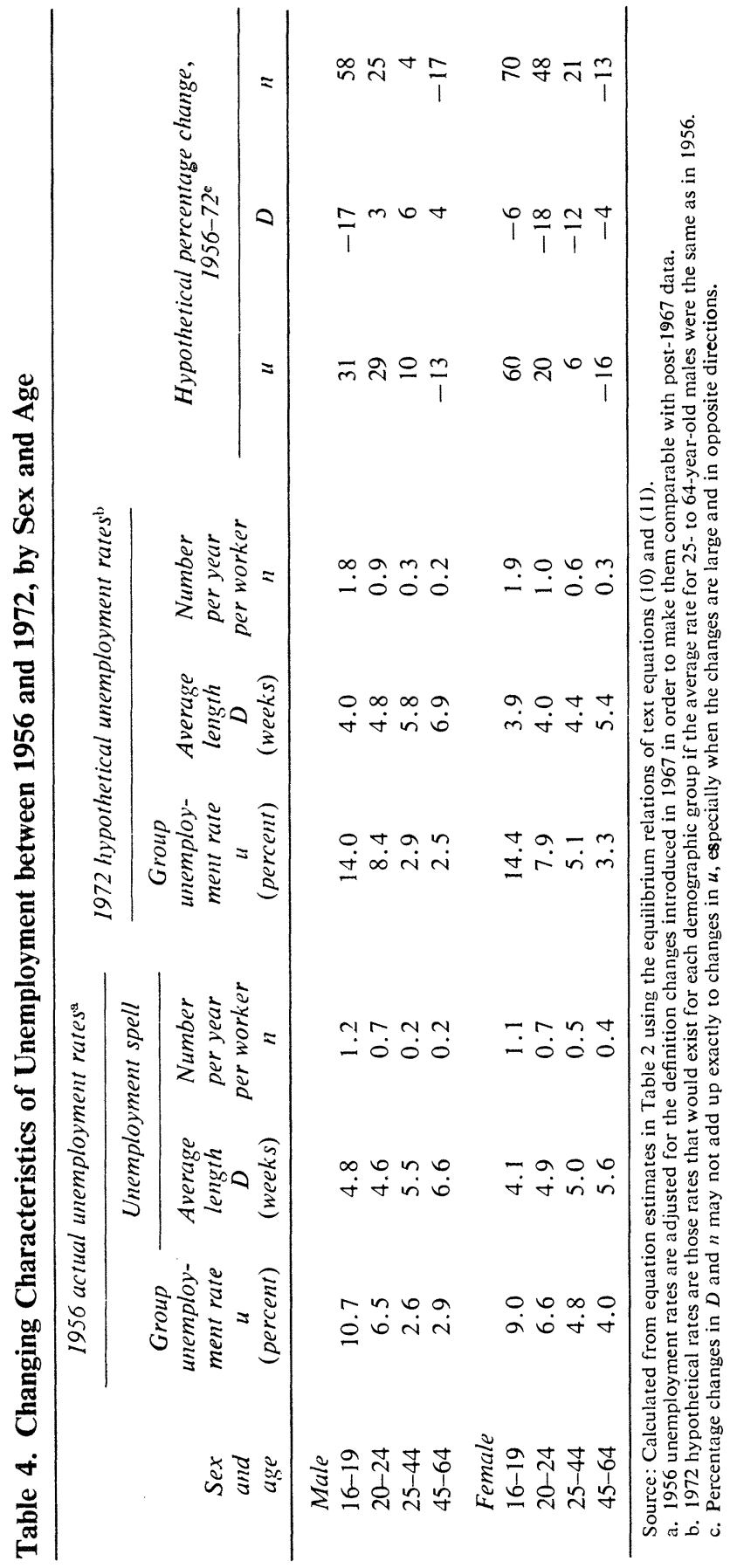


of the groups in the comparison made here. Like some eccentricity that grows sharper with time, the differences in the nature of unemployment experience among demographic groups have grown more marked; the groups with frequent spells have had the largest increase in the frequency of spells. These differences in the nature of the unemployment experience in different parts of the labor force are examined further below with the aid of some additional data.

\section{Spells and Flows through the Labor Market}

On some views of the labor market, all of the change in unemployment between two equilibrium levels would be accounted for by changes in the duration of unemployment spells. The number of spells would change only during the transition. A decline in the demand for labor, for example, would find the number of spells increasing as employers laid off workers in order to reach a new, desired level of employment. But once the unemployment rate reached its new equilibrium level, employers would return to their original rate of layoffs and turnover. The unemployed would suffer higher continuation rates than before and each of the original number of entrants would sustain the larger unemployment pool by staying unemployed longer. The finding that a large fraction of the change in unemployment between two equilibrium levels is accounted for by changes in the number of unemployment spells thus contradicts this view. And it lends support to the flow-probability model used here, which postulates that the cyclically sensitive employment probabilities that govern exits from unemployment also help determine the flow into unemployment. That model can now be reexamined in light of the empirical estimates that have been made.

The movement of workers out of unemployment has been viewed as a weekly lottery in which an unemployed worker draws a ticket that determines his chances of leaving unemployment. In the description of the probability model of unemployment above, the movement of workers into unemployment was viewed in a similar way, but with complications that can now be examined in light of the empirical results. To recapitulate, at any time, the job market receives a pool of workers who are looking for a new job but who have not yet been listed as unemployed. This pool results from the flow of entrants into the labor force and workers who terminate a job, either because they quit or because they are laid off. With the size of 
this flow per week, $F$, which is also the size of the pool of these persons, conceived as a stock, the average probability of one of these workers entering unemployment is $s$, where

$$
s=\frac{N}{F}
$$

or, as proportions of the labor force,

$$
s=\frac{n}{f} .
$$

In the spirit of the present model, it is tempting to approximate $s$ as proportional to $p$, the continuation rate parameter, since, in part, they measure the same thing: the probability that a worker will not find a job this week if he looks for one. However, the empirical results on spells warn against this approximation. From equation (13a),

$$
\frac{d n}{n}=\frac{d s}{s}+\frac{d f}{f} .
$$

But the cyclical changes in the number and duration of spells shown in Table 3 imply relatively much smaller changes in continuation rates. For instance, when the aggregate unemployment rate moves from 6 to 7 percent, the continuation rate for the oldest males changes by less than 1 percent and the number of spells by 12 percent; when the aggregate unemployment rate moves from 3 to 4 percent, the continuation rate changes by about 4 percent for some age groups and their number of spells changes by 25 or 35 percent. Thus the number of spells varies by far more than the continuation rate parameter when unemployment changes. According to equation (14), either the elasticity of $s$ with respect to unemployment is much greater than that of $p$, or the flow rate, $f$, has a substantial positive elasticity (over one-half) with respect to the unemployment rate.

The size of this flow, and its sensitivity to unemployment, is one of the intriguing and important mysteries of labor market analysis. Even data on gross changes in labor force status cannot measure it, since it includes workers who were employed two consecutive months but at different jobs.

For manufacturing industries, statistics are available on the number of workers joining this flow as a result of quits and layoffs from their previous jobs. As would be expected, when unemployment rises quits decline and layoffs increase. The net effect, however, is to reduce total separations. The elasticity of this part of the flow to unemployment is thus clearly negative if manufacturing experience is at all typical of the rest of the economy. 
The other component of the flow is entrants into the work force. Studies of participation rates reveal that the number of net entrants declines with rising unemployment. However, the number of net entrants is the difference between much larger numbers of gross entries and gross exits, each of which may change relatively little. The available statistics on gross change contain serious biases that can distort calculations of this kind. But even without evidence, it seems safe to assume that this elasticity, if positive at all, is not large enough both to offset the negative elasticity of separations to unemployment and to account for the rise in the number of spells implied by equation (14). The explanation of the high elasticity of $s$ with respect to unemployment that is implied by this equation lies in the nature of $s$ itself.

Part of the explanation comes from the changing composition of the flow of workers looking for jobs. For workers in each part of the pool, the weekly probability of finding a job can be related to the continuation rate parameter, $p$, and will vary cyclically with $p$. But those who enter the flow because they quit voluntarily have better lottery tickets than those who enter it because they are laid off. Since quits fall and layoffs rise when unemployment rises, the quality of the average lottery ticket of workers in the pool, described by $s$ in equation (14), will deteriorate more than proportionately to the change in $p$. The effect of this kind of shifting on the elasticity of $s$ with respect to unemployment is likely to be sizable. Quits dropped from almost 70 percent of the sum of quits and layoffs in 1969 to just over half in 1971.

Another source of greater elasticity for $s$ than for $p$ is the possibility of searching for work while on the job. If a worker who is to be laid off (or who plans to quit) has three weeks' notice and has a probability $(1-k p)$ of finding a new job in each of these weeks (where $p$ is the continuation rate parameter governing the chances of the unemployed and $k$ is a proportionality constant relating it to the chances of the average worker described here), the probability that he will not have found a job after one week is $k p$ and the probability that he will not have one when he separates is $k^{3} p^{3}$. This is his $s$ and its elasticity with respect to unemployment will be three times the elasticity of $p$.

These kinds of complications, along with the lack of any direct measure of the flow, $F$, mean that the part of the flow-probability model that governs new spells of unemployment must be inferred, as it has been here, rather than measured directly. But the results on spells support this view of the labor market process. 
This view also reveals some important differences between tight and loose labor markets that are not clearly revealed by unemployment rates themselves. The high elasticity of $s$ to unemployment rates means that the difficulty of changing jobs is strongly affected by labor market conditions. In a firm labor market, job cutbacks in some areas do not result in much unemployment because the workers affected easily find new jobs. And voluntary job shifts by workers seeking better jobs, or jobs to which they are better suited, are much more easily accomplished in firm labor markets.

\section{The Functioning of Labor Markets}

The findings on the nature of unemployment outlined above are consistent with current views of the labor market that stress the difference in the quality of jobs available to different groups of workers. This "dual theory" of the labor market explains high unemployment among some groups of workers by their inability to get jobs that have a promising future, the consequent frequency with which they change jobs, and the unemployment spells they suffer as they do. In this vein, Hall has argued that workers in groups with high unemployment rates have trouble not in finding jobs, but rather in keeping them, or in finding jobs worth keeping. ${ }^{11}$

The evidence on continuation rates and spells does show overwhelmingly that where unemployment is high, it is because workers are unemployed frequently, not because they continue unemployed for a long time as measured by the continuation rate parameter or average duration of spell. But two questions need closer examination. Are the frequent unemployment spells found in some groups the consequence of normal transitions? Such normal transitions in and out of the work force arise, for example, for persons enrolled in school or from job changes associated with a rational career-selection process. And do the relatively low continuation rates found for groups with high unemployment really mean jobs are easy to get for persons in these groups?

\section{CHANGING JOB PERMANENCE}

The evidence of Table 4 on the change in spells and duration that has taken place through the years bears on the first of these questions. The higher frequency of unemployment spells for most classes of secondary

11. Robert E. Hall, "Prospects for Shifting the Phillips Curve through Manpower Policy," Brookings Papers on Economic Activity (3:1971), pp. 659-701. 
workers suggests that the jobs these workers hold have become markedly more impermanent. While older workers-in particular men and women over 45-have, if anything, grown more securely attached to their jobs, most others have found their jobs increasingly transitory. ${ }^{12}$ This result makes it harder to accept an explanation for the high frequency of unemployment among secondary workers today as simply the consequences of normal transition for this group. Such an explanation would imply that the marked rise in the frequency of spells resulted from a marked rise in this norm. Since it is empty to regard any observation as a norm, this proposition would require some specific evidence to be acceptable.

The most obvious hypothesis to explain the greater frequency of unemployment spells for young workers is that the larger number of school enrollments has raised the normal number of labor force transitions for this group and thus raised the frequency of unemployment spells. Enrollment might increase transitions in two ways: most obviously by causing either transitions into and out of the labor market or job changes each summer when students left school; and also, possibly, by putting persons who work while enrolled into a less stable part of the job market than they would be in if not enrolled. I would guess that the first of these would be the more important possibility for explaining unemployment spells. In order to test it as the cause of more frequent spells, regressions like those of Table 2 were rerun for the four school age groups ( 16 to 19 and 20 to 24 years old, males and females), leaving out the observations for the four months, June through September. But the estimates from these regressions were similar to those in Table 2; in particular, for three of the four school age groups, the time trends leading to a rise in the frequency of unemployment spells were slightly larger than those in the whole-year regressions.

It still could be that similar individuals would experience the same frequency of unemployment today as before if their enrollment status were the same in both periods. But those not enrolled today are, on average, poorer job candidates than their counterparts of earlier years. Similarly, today's enrolled are poorer job candidates than their earlier counterparts. Settling all such possibilities calls for much more information. But the verdict of the original regressions--that weak job attachments and frequent spells are a growing problem-is not easily dismissed by reference to expanding school enrollment.

12. Unfortunately, these data are not broken down by race, so that the recognized problem of poor jobs and high turnover for blacks cannot be examined over time. 


\section{ARE DROPOUTS PURELY VOLUNTARY?}

The significance of frequent labor force transitions can be examined in a context more general than school enrollments. It is true that the high unemployment groups are also groups whose workers display a relatively impermanent attachment to the work force. These transitions in and out of the work force increase their chances of being unemployed. But to what extent do they exit frequently from the work force because they do not wish to work rather than because they are frustrated in finding work? Interpreted most strictly, the hypothesis that labor force leavers drop out because they choose not to work would predict that an employed individual is as likely to drop out as one who is unemployed. This is a very strong version of the hypothesis, and testing it might be interpreted as a test of whether dropouts are purely voluntary in the sense that their decisions are not influenced by their prospects of finding jobs. ${ }^{13}$

This hypothesis was tested using data on gross changes in labor force status. ${ }^{14}$ These data contain some unknown biases and probably cannot be relied on to settle close questions. This one turned out not to be close at all. The ratio of the number of workers who were unemployed last month and out of the labor force this month to last month's unemployment gave the probability of an unemployed worker dropping out. Similarly, the ratio of those employed last month and out of the labor force this month to last month's employment gave the probability of an employed worker dropping out. The two probabilities for various demographic groups are shown in Table 5 .

Teenagers come nearest to fitting the hypothesis, indicating that many of them do leave the work force because they no longer want a job. The difference in the probability of dropping out for unemployed compared with employed individuals grows with age for both men and women. Qualitatively, this pattern in the two youngest groups is what would be expected from school enrollment and having babies. Once these reasons are allowed for, most people plainly leave the work force only after first becoming unem-

13. A person is considered out of the labor force in a given month if, at the time of the monthly employment survey, he is not employed and did not engage in job-seeking activity during the previous month. If he did look for a job, he is in the labor force as an u.employed person. He is a dropout this month if he was in the labor force last month and not this month.

14. I am grateful to John E. Bregger of the Bureau of Labor Statistics for his help in making available the unpublished gross change data. 
Table 5. Monthly Probability of Dropping o $t$ of Labor Force, by Sex and Age Group, Average for 1968-71

\begin{tabular}{|c|c|c|c|c|c|c|}
\hline \multirow{3}{*}{$\begin{array}{l}\text { Previous } \\
\text { employment } \\
\text { status }\end{array}$} & \multicolumn{6}{|c|}{ Sex and age } \\
\hline & \multicolumn{3}{|c|}{ Males } & \multicolumn{3}{|c|}{ Females } \\
\hline & $16-19$ & $20-24$ & $25-59$ & $16-19$ & $20-24$ & $25-59$ \\
\hline Employed & 0.13 & 0.04 & 0.01 & 0.16 & 0.07 & 0.05 \\
\hline Unemployed & 0.33 & 0.16 & 0.10 & 0.39 & 0.31 & 0.35 \\
\hline
\end{tabular}

Source: Calculated from unpublished gross change data from U.S. Bureau of Labor Statistics.

ployed. Rather than being an important cause of unemployment, such transitions appear to result from it.

\section{UNEMPLOYMENT OF ENTRANTS}

The counterpart of frequent exits from the work force is frequent entries. Because secondary workers move in and out of the work force more frequently than others, their relatively high unemployment rates are sometimes explained in terms of their large number of entrants. In the monthly series, "Unemployed Persons, by Reason for Unemployment," which has been published regularly by the Bureau of Labor Statistics since 1967, the unemployed are categorized by those who left their last job, lost their last job, entered the labor force for the first time, or reentered it. Analyses of these data have noted that the high unemployment rates for entrants are the predominant source of high rates among secondary workers, particularly young workers, and that differences in these rates for entrants account for most of the difference in overall unemployment rates among demographic groups in the labor force. ${ }^{15}$ Table 6 sets out unemployment rates by reason averaged over the four years 1968-71 for a more detailed breakdown of the labor force than is available in the published statistics. While unemployed new entrants and reentrants account for only 15 percent of total unemployment of prime-age males, they account for between 67 and 80 percent of unemployment in the teenage groups, and for a substantial fraction of unemployment of other workers. The ratio of unemployed entrants to total unemployment is remarkably similar for black and

15. Kathryn D. Hoyle, "Job Losers, Leavers, and Entrants-A Report on the Unemployed," Monthly Labor Review, Vol. 92 (April 1969), pp. 24-29. 
Table 6. Unemployment Rates by Reason, by Color, Sex, and Age, 1968-71 Average

\begin{tabular}{cccccccc}
\hline $\begin{array}{c}\text { Color, } \\
\text { sex, } \\
\text { and } \\
\text { age }\end{array}$ & $\begin{array}{c}\text { Lost } \\
\text { job }\end{array}$ & $\begin{array}{l}\text { Left } \\
\text { job }\end{array}$ & $\begin{array}{c}\text { New } \\
\text { entrant }\end{array}$ & $\begin{array}{c}\text { Re- } \\
\text { entrant }\end{array}$ & $\begin{array}{c}\text { All } \\
\text { entrants }\end{array}$ & $\begin{array}{c}\text { All } \\
\text { reasons }\end{array}$ & $\begin{array}{c}\text { Ratio of } \\
\text { unemployed } \\
\text { entrants } \\
\text { to total } \\
\text { unemployment }\end{array}$ \\
\hline $\begin{array}{cccccccc}\text { White } \\
\text { Male }\end{array}$ & & & & & & & \\
16-19 & 2.60 & 1.41 & 3.96 & 4.27 & 8.23 & 12.24 & 0.67 \\
$20-24$ & 2.85 & 1.12 & 0.43 & 2.20 & 2.64 & 6.61 & 0.40 \\
$25-64$ & 1.61 & 0.30 & 0.02 & 0.31 & 0.33 & 2.24 & 0.15 \\
Female & & & & & & & \\
$16-19$ & 1.65 & 1.37 & 6.04 & 3.97 & 10.02 & 13.04 & 0.77 \\
$20-24$ & 1.67 & 1.44 & 0.56 & 3.00 & 3.56 & 6.66 & 0.53 \\
$25-64$ & 1.59 & 0.51 & 0.10 & 1.43 & 1.53 & 3.62 & 0.42 \\
Nonwhite & & & & & & & \\
Male & & & & & & & \\
$16-19$ & 5.01 & 2.68 & 7.67 & 8.98 & 16.66 & 24.35 & 0.68 \\
$20-24$ & 5.98 & 1.71 & 0.94 & 2.76 & 3.70 & 11.39 & 0.32 \\
$25-64$ & 2.90 & 0.45 & 0.06 & 0.60 & 0.65 & 4.01 & 0.16 \\
Female & & & & & & & \\
$16-19$ & 3.32 & 2.97 & 13.77 & 11.51 & 25.28 & 31.57 & 0.80 \\
$20-24$ & 3.85 & 2.31 & 1.75 & 6.21 & 7.96 & 14.12 & 0.56 \\
$25-64$ & 2.24 & 0.83 & 0.23 & 2.28 & 2.51 & 5.58 & 0.45 \\
\hline
\end{tabular}

Source: Derived from worksheets supplied by the U.S. Bureau of Labor Statistics. Details may not add to totals because of rounding.

white workers in each of the age-sex groups, despite substantial differences in the unemployment rates of blacks and whites.

While much of the unemployment of secondary workers, particularly of young workers, thus can be identified with entrance into the labor force, this finding tells less than it seems to. Each unemployment rate by reason has as its denominator the total labor force of the particular demographic group. Thus, the rates for all the reasons add up to the total unemployment rate for the group. For any demographic group in Table 6, the unemployment rate by reason can be decomposed as follows:

$$
\frac{U_{r}}{L}=\left(\frac{U_{r}}{L_{r}}\right)\left(\frac{L_{r}}{L}\right)
$$

where the subscript $r$ denotes a reason. The unemployment rate for entrants can be relatively high either because an average entrant has a high probability of being unemployed relative to other workers or because there 
are many entrants relative to other workers. It is useful to know how much is contributed by each of these factors.

To answer this question, data on gross changes in labor force status are again needed. They permit calculation of the number of unemployed in a given month who were not in the labor force the previous month. This concept of unemployed entrants does not correspond to the number of entrants unemployed in the data of Table 6 for two reasons: The table lists as an entrant any person unemployed in a given month who was not in the labor force before becoming unemployed. Thus, it includes workers who were unemployed the previous month, and perhaps the month before that as well, so long as they were out of the labor force before initially entering unemployment. Second, the gross change data do not distinguish between entrants and reentrants as do the data in Table 6.

The great advantage of the gross change data is that they permit calculation of an unemployment rate for entrants as the ratio of unemployed entrants to total entrants. This reflects the difficulty entrants have in finding jobs, which the data on unemployment by reason do not. Except that it refers only to those unemployed who entered the work force this month, this gross change measure of an unemployment rate for entrants corresponds to $U_{r} / L_{r}$ in equation (15), which decomposed the "reasons" definition of unemployment rates. An unemployment rate for nonentrants also can be described analogously as the ratio of unemployed nonentrants to total nonentrants.

The difference in total unemployment rate between two labor force groups can now be decomposed into the parts due to differences in unemployment rates for entrants, in unemployment rates for nonentrants, and in the proportion of entrants in the work force. Table 7 does this for the differences in unemployment rates between 25- to 59-year-old white men and each of eleven other demographic groups. For each group, the difference due to each factor in Table 7 is computed as follows:

(a) The difference due to the unemployment rate of entrants is the proportion of entrants in the group's labor force times the difference between unemployment rates for entrants for the group and for white men 25 to 59 .

(b) The difference due to the unemployment rate for nonentrants is parallel to (a), using the relevant unemployment rates.

(c) The difference due to number of entrants is the difference between 
the proportion of entrants in the work force of the group and the proportion for white men 25 to 59 , times the difference between the unemployment rates for entrants and nonentrants for the group.

Since the table is based entirely on comparisons of the same concept between two different demographic groups, the problem of bias in the gross change data should be minimized. However, the difference in definitions, compared with the concepts in Table 6, will affect some of the numbers in the table in a way that should be noted. Unemployment totals for each group and the disparities in total unemployment rates between any two groups match up very closely in the two tables, as they should. The number of entrants and the proportion of them unemployed will be lower with the Table 7 definitions of entrants. With the symbols $O, E$, and $U$ used for out of the work force, employed, and unemployed, respectively, Table 7 counts only $O U$ individuals as unemployed entrants, while the proper total is

Table 7. Allocation of Unemployment Disparities by Characteristics of Entrants and Nonentrants, by Color, Sex, and Age, 1968-71 Average

Percent

\begin{tabular}{|c|c|c|c|c|}
\hline \multirow[b]{2}{*}{$\begin{array}{c}\text { Color, sex, } \\
\text { and age }\end{array}$} & \multirow{2}{*}{$\begin{array}{c}\text { Total } \\
\text { unemployment } \\
\text { rate disparity vs. } \\
\text { 25-59-year-old } \\
\text { white males }\end{array}$} & \multicolumn{3}{|c|}{ Source of difference ${ }^{\mathrm{a}}$} \\
\hline & & $\begin{array}{c}\text { Entrants' } \\
\text { unemployment } \\
\text { rate }\end{array}$ & $\begin{array}{l}\text { Nonentrants' } \\
\text { unemployment } \\
\text { rate }\end{array}$ & $\begin{array}{c}\text { Number } \\
\text { of } \\
\text { entrants }\end{array}$ \\
\hline \multicolumn{5}{|l|}{ White } \\
\hline \multicolumn{5}{|l|}{ Male } \\
\hline $16-19$ & 9.8 & 0.0 & 6.0 & 2.9 \\
\hline $20-24$ & 4.1 & 0.0 & 3.1 & 0.9 \\
\hline \multicolumn{5}{|l|}{ Female } \\
\hline $16-19$ & 11.0 & 0.9 & 5.4 & 4.5 \\
\hline $20-24$ & 4.2 & 0.2 & 2.2 & 1.8 \\
\hline $25-59$ & 1.5 & -0.4 & 0.6 & 1.0 \\
\hline \multicolumn{5}{|l|}{ Nonwhite } \\
\hline \multicolumn{5}{|l|}{ Male } \\
\hline $16-19$ & 21.8 & 3.3 & 13.0 & 5.4 \\
\hline $20-24$ & 8.7 & 0.5 & 7.1 & 1.2 \\
\hline $25-59$ & 1.8 & 0.0 & 1.5 & 0.2 \\
\hline \multicolumn{5}{|l|}{ Female } \\
\hline $16-19$ & 28.6 & 6.6 & 14.9 & 8.4 \\
\hline $20-24$ & 11.9 & 1.9 & 7.5 & 3.5 \\
\hline $25-59$ & 3.6 & 0.1 & 1.9 & 1.5 \\
\hline
\end{tabular}

Source: Calculated from unpublished data on gross changes from U.S. Bureau of Labor Statistics. a. Sum of differences does not equal total due to interactions. 
$(O U+O U U+\ldots)$, which counts everyone who has been in no status other than unemployment since entering. Similarly, in Table 7 the category nonentrants will count the $O U U$ types when it should not. The discrepancy will not be uniform among the demographic groups since the proportion of OUU types will vary. The Table 7 data must be interpreted with this in mind. One implication is that the ratio of the unemployment rate for entrants to that for nonentrants will be somewhat lower by the Table 7 definitions, with the distortion larger for groups having relatively many entrants. If weekly continuation rates, $p$, are about 0.75 , in one month about onethird $\left(p^{4}\right)$ of the $O U$ s will have become $O U U$ s. This gives a rough measure of the discrepancy.

Table 7 shows that differences in unemployment rates for entrants are not an important source of total differences in unemployment. The adjustments just discussed would not alter this conclusion, although they would enlarge slightly the differences shown in the tables. Only for young blacks is the probability of an entrant finding a job markedly different from the probability for an entrant in any other group. The unemployment rate for entrants who are men over 25 must be a statistic based on an unrepresentative sample of workers in this age group, since most workers in this group are in the labor force by the time they reach this age group, and remain in it until retirement. But that should not seriously distort the implications of the rest of the table. The last column demonstrates that the different proportion of entrants does account for a noticeable portion of total differences in unemployment, but still not the major portion. The largest part of differences in unemployment arises from differences in the unemployment rates of nonentrants, workers unemployed one month who were either working or unemployed the previous month. Thus, unemployment disparities do not seem to be explainable simply in terms of weak attachments to the work force by some workers, particularly in view of the finding that much of what weakness there is in attachment apparently stems from poor employment opportunities.

\section{Employment Probabilities}

The analysis of unemployment that has been built around the continuation rate parameter must be amended before results like those on the frequency and duration of spells for different groups can be interpreted in 
terms of the difficulty of finding a job. Duration of spell varies directly with continuation rates, so the groups with relatively low durations have relatively low probabilities of continuing unemployed each week. But workers leave unemployment either because they find jobs or because they leave the work force. The gross change data offer some evidence on the importance of each of these two avenues out of unemployment. Again, the possibility that unknown bias in the data distorts the conclusions can be minimized by a comparison of the same statistic for various demographic groups. Table 8 analyzes the flows out of unemployment for twelve demographic groups. Probabilities are shown for 1968 and 1971, the two most dissimilar years for which data were available.

The first column lists the probability that a worker who is unemployed one month will leave unemployment by the next month. This probability, labeled $L$, is calculated as the ratio of workers unemployed last month but not this month to total unemployment last month. Conceptually, $L$ is related to the continuation rate, $p$, by the following argument: A worker unemployed at the time of last month's survey has a probability $p$ (or $q=$ $p / m$ if he has already been unemployed more than four weeks) of being unemployed a week later; a probability $p^{2}$ of being unemployed two weeks later; a probability $p^{3}$ of being unemployed three weeks later; and a probability $p^{4}$ of being unemployed at the time of this month's survey if there are four weeks between surveys this month. The probability that he will have left unemployment is thus $1-p^{4}$ (or actually between $1-p^{4}$ and $\left.1-q^{4}\right)$, which should be equal to $L$. Because $L$ and $p$ do not come from the same body of data and because the intervals between surveys average 4.3 weeks rather than 4 weeks, this formula will not hold exactly. But the orders of magnitude of $L$ shown in the table are close enough to what this formula would predict to provide some confidence in Table 8. For example, for males aged 16 to 19 , continuation rates were $p=0.69$ and $q=0.82$ in 1968; an equally weighted average of $1-p^{4}$ and $1-q^{4}$ is 0.66 , which is just below the value of $L$ for white males in that age group. For 1971, continuation rates were $p=0.73$ and $q=0.87$, which by the same calculations predict $L=0.58$, precisely the value in the table. Predictions were not this exact for all groups; but orders of magnitude were right, as were the changes between the two years.

The next two columns in Table 8 break down $L$ into the two avenues for leaving unemployment: the monthly probability of an unemployed worker being hired, $H$, and dropping out of the work force, $O$. These are calculated 
Table 8. Monthly Probability of an Unemployed Worker Leaving Unemployment, by Color, Sex, and Age, 1968 and 1971

\begin{tabular}{|c|c|c|c|}
\hline \multirow[b]{2}{*}{$\begin{array}{l}\text { Color, sex, } \\
\text { and age }\end{array}$} & \multirow{2}{*}{$\begin{array}{c}\text { Total } \\
\text { probability } \\
\text { of leaving } \\
\text { unemployment }\end{array}$} & \multicolumn{2}{|c|}{$\begin{array}{c}\text { Probability of leaving unemployment, } \\
\text { by reason }\end{array}$} \\
\hline & & $\begin{array}{l}\text { Being hired } \\
\qquad H\end{array}$ & $\begin{array}{l}\text { Dropping out } \\
O\end{array}$ \\
\hline & & White & \\
\hline \multicolumn{4}{|l|}{ Males } \\
\hline \multicolumn{4}{|l|}{$16-19$} \\
\hline 1968 & 0.67 & 0.34 & 0.33 \\
\hline 1971 & 0.58 & 0.28 & 0.30 \\
\hline \multicolumn{4}{|l|}{$20-24$} \\
\hline 1968 & 0.64 & 0.48 & 0.16 \\
\hline 1971 & 0.50 & 0.35 & 0.15 \\
\hline \multicolumn{4}{|l|}{$25-59$} \\
\hline 1968 & 0.56 & 0.46 & 0.10 \\
\hline 1971 & 0.42 & 0.34 & 0.08 \\
\hline \multicolumn{4}{|l|}{ Females } \\
\hline \multicolumn{4}{|l|}{ 16-19 } \\
\hline 1968 & 0.68 & 0.30 & 0.38 \\
\hline 1971 & 0.64 & 0.26 & 0.38 \\
\hline \multicolumn{4}{|l|}{$20-24$} \\
\hline 1968 & 0.66 & 0.37 & 0.29 \\
\hline 1971 & 0.57 & 0.29 & 0.28 \\
\hline \multicolumn{4}{|l|}{$25-59$} \\
\hline 1968 & 0.66 & 0.31 & 0.35 \\
\hline \multirow[t]{2}{*}{1971} & 0.53 & 0.24 & 0.29 \\
\hline & \multicolumn{3}{|c|}{ Nonwhite } \\
\hline \multicolumn{4}{|l|}{ Males } \\
\hline \multicolumn{4}{|l|}{$16-19$} \\
\hline 1968 & 0.65 & 0.29 & 0.36 \\
\hline 1971 & 0.58 & 0.19 & 0.39 \\
\hline \multicolumn{4}{|l|}{$20-24$} \\
\hline 1968 & 0.62 & 0.45 & 0.17 \\
\hline 1971 & 0.41 & 0.22 & 0.19 \\
\hline \multicolumn{4}{|l|}{$25-59$} \\
\hline 1968 & 0.56 & 0.43 & 0.13 \\
\hline 1971 & 0.43 & 0.31 & 0.12 \\
\hline \multicolumn{4}{|l|}{ Females } \\
\hline \multicolumn{4}{|l|}{$16-19$} \\
\hline 1968 & 0.62 & 0.18 & 0.44 \\
\hline 1971 & 0.60 & 0.16 & 0.44 \\
\hline \multicolumn{4}{|l|}{$20-24$} \\
\hline 1968 & 0.62 & 0.26 & 0.36 \\
\hline 1971 & 0.53 & 0.19 & 0.34 \\
\hline \multicolumn{4}{|l|}{$25-59$} \\
\hline 1968 & 0.64 & 0.27 & 0.37 \\
\hline 1971 & 0.54 & 0.20 & 0.34 \\
\hline
\end{tabular}


from the gross change data as the ratio to last month's unemployment of workers unemployed last month but employed this month $(H)$ and workers unemployed last month but out of the work force this month $(O)$. By definition, $L=H+O$. The table shows that different demographic groups use these two avenues out of unemployment in distinctly different proportions. Most important, the relatively short unemployment durations calculated for most secondary workers are not the result of higher probabilities of getting a job. The rank ordering of groups according to $L$ in Table 8 or duration in Table 3 is scrambled and very nearly reversed in the ordering according to hire probabilities, $H$, in Table 8 . In particular, males over 25 have virtually the best hire probabilities, although they had the longest durations and highest continuation rates among demographic groups. The short spells of younger workers do not reflect good lottery tickets in the employment pool; they have the lowest hire probabilities in Table 8. Rather, their spells are short, on average, because they often terminate them quickly by leaving the work force.

These results are especially telling in view of the a priori reasons for expecting longer search times for primary workers. They can be expected to search more thoroughly because they are more concerned to find the right job since it is more likely to be a permanent attachment for them than for other workers; and they are more likely to receive unemployment compensation while they look for work. Despite such considerations, they appear to find jobs more quickly than workers with more frequent spells of unemployment.

The experience of nonwhite workers revealed by Table 8 is particularly disappointing. Their probabilities of leaving unemployment, $L$, and hence the average durations of their unemployment spells, are not drastically different from those of whites in the same age-sex group. This means the large differences in unemployment rates between whites and blacks, such as those shown in the "all reasons" column of Table 6 , arise primarily because blacks suffer more frequent unemployment spells. But in addition, their hire probabilities, $H$, show that the comparable unemployment durations of blacks and whites conceal differences in the probabilities of finding jobs. Particularly for blacks under 25 , hire probabilities are noticeably worse than they are for whites of the same age and sex. The differences are especially marked in the weak labor markets of 1971 . Bad as they reveal the unemployment experience of blacks to be, conventional unemployment statistics conceal an even worse employment outlook. 


\section{Comments and Discussion}

Robert E. Hall: This paper makes a substantial contribution to our understanding of unemployment, particularly of the changes in its character over the past sixteen years. Perry's careful analysis makes it possible to break down the published unemployment rates for various demographic groups into the frequency of unemployment on the one hand and the duration on the other. Modern thinking about unemployment has made us aware of the need for this distinction, but Perry's work is the most successful by far in actually carrying it out. His finding that the deterioration in the unemployment rates of young workers relative to those of older workers is associated entirely with an increase in frequency rather than in duration is quite striking and is in accord with recent speculation about the importance of turnover among young workers.

Throughout the paper, Perry argues that increased turnover among young workers is not necessarily a reflection of decreased attachment to the labor force. An undercurrent of recent thinking, with which Perry is clearly not sympathetic, holds that the increased turnover of teenagers is a voluntary response to a changing economic environment. Rising family incomes and increasingly attractive opportunities outside the labor force make it less necessary and less appealing for teenagers to work steadily, according to this view. While I am no more sympathetic than Perry is to this hypothesis or to its implication that federal policy need not concern itself with the worsening position of teenagers, I am not fully convinced by the evidence he presents.

Perry looks briefly at the part higher enrollment in school plays in increasing turnover. A large fraction of teenagers in school look for summer jobs once a year, and many look for jobs after school several times a year as well. Perry simply eliminates the summer months and finds that his con- 
clusions are unaffected. This tells us that turnover in October through May has risen about as fast as it has over the whole year. It does not evaluate the contribution of school to turnover during the nonsummer months-in particular, it neglects after-school unemployment, which in October is about half the total teenage unemployment.

Perry is correctly concerned with what happens to teenagers when they leave unemployment. It is too easy to interpret data on the duration of unemployment as if they measured the time necessary to find jobs. Every month, a fraction of those unemployed drop out of the labor force rather than finding work. Perry's data, taken from the compilation of gross flows in the household survey, suggest that this fraction is quite large for teenagers. He draws two conclusions from this finding: First, the fact that unemployed teenagers are more likely to drop out of the labor force than employed teenagers suggests that turnover among teenagers is not a voluntary response to opportunities outside the labor market but rather is a response to the unsatisfactory opportunities in the labor market. Second, he concludes that the duration of job-finding is longer for teenagers than for adults, even though the duration of unemployment is slightly less. Again, he argues that this is evidence of lack of employment opportunities for young workers.

I find this part of the paper somewhat weakened by lack of caution in interpreting the data on teenage unemployment. Part of Perry's findings from the data on gross flows could be explained by random errors in classifying teenagers into unemployed and out of the labor force. If a teenager is incorrectly classified as unemployed in one month and correctly classified as not in the labor force the next month, he will count in Perry's data as a dropout from unemployment. There does not seem to be any compensating bias in the opposite direction. I cannot cite any evidence that bears directly on this point, but I know that there are substantial problems in general in measuring unemployment among teenagers. For example, a special survey in October 1967 found 418,000 unemployed teenagers in school and 108,000 out of school, for a total of 526,000 . By contrast, the regular household survey found 262,000 in school and 170,000 out of school for a total of 432,000. ${ }^{1}$ Both surveys were conducted by the Bureau of the Census; the major difference seems to be that in the special survey the teenagers themselves were in-

1. Career Thresholds, Manpower Research Monograph No. 16, Vol. 2 (U.S. Department of Labor, 1970), Table A-3, p. 92. 
terviewed while in the household survey it is usually the mother of the teenager who responds.

Errors in the data may not affect Perry's second conclusion cited above. If the data are contaminated by many false short spells of unemployment, then they may conceal the fact that the true spells are long. The first conclusion, however, is quite sensitive to errors.

Perry argues that high unemployment among teenagers cannot be attributed to the high proportion of entrants to the labor force among the unemployed, nor to the high unemployment rates suffered by entrants. Again, he believes that these interpretations cast doubt on the hypothesis that voluntary movements in and out of the labor force are the main cause of high unemployment among teenagers. He performs a considerable service by calculating, for the first time as far as I know, the unemployment rates for entrants and nonentrants. He finds that unemployment is equally high among entrants and nonentrants for teenagers, low for adult nonentrants, and high for adult entrants. Further, the proportion of entrants among teenagers is much higher. It strikes me that his conclusion from these data that all the differences between teenagers and adults can be attributed to the experience of teenage nonentrants is spurious. He poses three questions:

(a) What would happen if teenage entrants had the same unemployment rate as adult entrants?

(b) What would happen if teenage nonentrants had the same unemployment rate as adult nonentrants?

(c) What would happen if the proportion of entrants among teenagers were the same as the proportion among adults?

The answers, given in Perry's Table 7, are:

(a) Nothing much, since the rates among entrants are about the same.

(b) A great deal, since the rates are quite different.

(c) Nothing much, since teenage entrants and nonentrants have about the same rates.

To illustrate the fallacy of this approach, I give three alternative questions:

$\left(a^{\prime}\right)$ What would happen if adult entrants had the same unemployment rate as teenage entrants?

$\left(b^{\prime}\right)$ What would happen if adult nonentrants had the same unemployment rate as teenage nonentrants?

$\left(c^{\prime}\right)$ What would happen if the proportion of entrants among adults were the same as the proportion among teenagers? 
The answers are

$\left(a^{\prime}\right)$ Nothing much, since the rates are about the same.

(b') Quite a bit, since the rates are different.

(c') Quite a bit, since the rate is so much higher among adult entrants than among adult nonentrants. If Perry had done my calculations (which I find at least as appealing as his) rather than his own, he would have apportioned the blame for high teenage unemployment between the high rates for nonentrants and the high proportion of entrants.

In summary, the paper sheds a good deal of new light on the nature of unemployment differentials and their change over time. I am not fully convinced by Perry's attempts to interpret his findings as refuting the hypothesis that teenage unemployment is worsening because of increasing voluntary turnover.

Charles Holt: In this paper George Perry focuses on the stock of unemployed workers and explores the flows into and out of unemployment and its duration for various age and sex groups. In doing this he shows clearly and dramatically the dynamic character of most unemployment. For most workers, unemployment is a state through which many pass, rather thanand this is certainly fortunate in welfare terms-a condition that constitutes a chronic problem for a fixed group of workers.

However, we cannot take much comfort from the dynamic picture that the search-turnover theory of the labor market yields, because as Perry's work shows, many people "solve" their unemployment problems not by securing work but by dropping out of the labor force. Indeed, the flows into and out of the labor force are important components of the turnover phenomenon, which puts a heavy load on labor markets and contributes to the waste and frustration of unemployment.

Within the constraints of his exclusive focus on unemployment and tabulated data largely from the Current Population Survey (CPS), Perry has made an important contribution in illuminating the fine-grain structure of one of our national policy variables. Since he has presented his analysis clearly, there is little need for a discussant to add highlights. Consequently, I will instead raise some issues that qualify the results and point toward the need for further work. The comments are offered in the spirit of contributing to what could be a follow-up to Perry's work here.

The assumption is made in his equation (6) that the probability of continuing unemployed for unemployment spells of short duration (four weeks 
or less) changes in proportion to that probability for unemployment spells of longer duration. However, since the active behavior is in leaving unemployment, the proportional movements of probabilities are much more likely to be in terms of the probabilities of not continuing unemployed. Thus his (6) should be replaced by

$$
(1-p)=m(1-q) \text {. }
$$

This formulation follows from behavioral relations that explain the changes in worker status that are involved in being hired or dropping out-not the probability of no change in status.

One of the advances that Perry has made is in noting that unemployment continuation rates rise with unemployment duration, and incorporating this explicitly in his theory as a discrete jump in the continuation rate after the first month. Treating time in discrete weeks, he then obtains a single equation (7), which relates five variables: the continuation rate, the ratio of short- to long-term continuation rates, short-term unemployment, longterm unemployment, and total unemployment a week previously. The second variable is estimated using another study and is assumed to be the same for all groups of workers; the third and fourth variables are observed directly in samples of the Current Population Survey; linear interpolation without any particular justification is used to supply the fifth variable. Then the equation is solved for the roots of a fourth-order polynomial, and Perry selects the "right one" to obtain an estimate of the short-term continuation rate. This all sounds pretty complex, and it is. It would be so difficult to determine the statistical properties of his estimators that the accuracy of his estimates of continuation probability is hard to judge rigorously. I have no doubt, however, that his estimates are reasonable, although the theoretical premise of his equation (6) that was discussed above may be a serious misspecification. Since unknown biases may affect the estimates of the continuation rate, calculated from equation (7), that serve as the dependent variable in the subsequent analysis and are the basis for estimating unemployment duration and turnover flows, Perry's empirical results should be treated carefully until they can be crosschecked by other methods.

The key question is whether a simple theoretical formulation can be developed whose parameters have derivable statistical properties and can be estimated directly from available data without interpolation, use of "outside" estimates, or the unreasonable assumptions that the continuation rate rises for long duration unemployment by the same ratio for all groups of 
workers. Presumably Perry could handle the alternative version of his equation (6) within his formulation.

To explore quickly the feasibility of such a formulation, I assumed initially that the unemployment continuation rate was constant for a group of workers and time was continuous. From these flow relations I obtained by integration the following equilibrium relation

$$
\frac{U(T)}{U}=e^{-(1-p) T},
$$

where $U(T)$ is the amount of unemployment whose duration is longer than $T$ and $U$ is total unemployment.

This corresponds to Perry's equation (7), whose family resemblance is evident when we note that his middle term is relatively small.

Taking logarithms of (2) yields

$$
\ln [U / U(T)]=(1-p) T,
$$

which would lead us to expect a linear proportional relation if $U / U(T)$ were plotted against $T$ on a semilog graph. However, some preliminary experiments with data on unemployment by duration confirmed the presence of rising continuation rates that Perry has postulated.

One simple way to modify the above theory to take account of this fact is to assume that search time for the unemployed does not move synchronously with calendar time, but is related to it in a simple nonlinear way. For example, unemployment search "duration," $T$, might be related to calendar time, $t$, by

$$
T=t^{k},
$$

where $k$ is less than unity so that more and more calendar time is needed for each incremental unit of effective search time. In order to test this formulation (4) was substituted into (3) to eliminate nonobservable search time, $T$, and to obtain a relation in calendar time. This gives us

$$
\ln \left\{U / U\left[(t)^{k}\right]\right\}=(1-p) t^{k} .
$$

Since each month we have observations of the unemployment ratio for three different (calendar) durations, by taking logs again we can estimate the parameters $p$ and $k$ using linear regression. With data for unemployed males, aged 25-44, in all Januarys from 1968 to 1971, the fit was very good $\left(R^{2}>0.943\right)$ as would be expected from the high ratio of parameters to ob- 
servations; but significantly the four independent estimates of $k$ covering a three-year interval ranged from 0.849 to 0.910 , which lends credibility to the model. Combining these results, and using Perry's notation, yields an expression comparable to his equation (7):

$$
p=1+\frac{\ln \left(U^{* *} / U\right)}{(4.5)^{k}},
$$

where from the January data I looked at, $k$ appears to be of the order of 0.9 and 4.5 is an estimate of the actual weeks of unemployment represented by the survey break between four- and five-week durations. If we are prepared to take $k$ as a constant, the estimate of the initial continuation rate provided by equation (6) is relatively simple, requires only available data, and takes account of the continuous rise in the continuation rate (expressed in terms of calendar time).

Integrating the function for the outflow of workers under this model assuming a constant inflow yields an expression for duration:

$$
D=\frac{U}{N}=\frac{\Gamma(1 / k)}{(1-p)^{1 / k}}=\frac{0.951}{(1-p)^{1.1}}
$$

where $\Gamma(\quad)$ is the integrated Gamma function and in the right-hand expression we have substituted our rough estimate of $k=0.9$. This expression is comparable to Perry's much more complicated equation (11), and when $k$ is unity this duplicates his equation (11a).

As we found above, the value of $k$ can be estimated directly from the CPS data for each demographic group. Time has not allowed the testing of the formulation that I have proposed, but it appears that some of the difficulties that Perry encountered can be surmounted.

Having worked out a model for predicting turnover and duration from the unemployment continuation rate, Perry next turns to finding relations for predicting that probability from unemployment-although he recognizes that causality runs in the opposite direction as well. While Perry recognizes the role of vacancies in determining continuation rates, he does not make explicit use of search theory models in formulating his relation. Instead, in Table 1, he reports a raw empirical search for best fit, using various functional forms of both dependent and independent variables. The theory of labor market dynamics is not well developed, but at this late date it is a bit depressing to see the issue of theoretical specifications so lightly treated in econometric work. 
A simple model of the labor market can be readily formulated that would throw some light on both functional forms and lag structures.

For example, the following relations for exits from unemployment, $N_{0}$,

$$
N_{0}=a V^{b} U^{1-b}
$$

and for $N_{i}$, the turnover flow from employment, $E$, into unemployment,

$$
N_{i}=c\left(\frac{V}{U}\right)^{d} E
$$

where $a, b, c$, and $d$ are constants, would yield, by the elimination of vacancies, $V$, approximately the formulation that Perry selected in equation (12) by a goodness-of-fit criterion. Greater theoretical insight into the processes that generate the data should improve the quality of our estimates and our interpretation of them. ${ }^{1}$

Although the many empirical and theoretical issues that Perry's work is concerned with are far from settled, he clearly displays the fact that different groups of workers have substantially different experiences both on the job, as reflected in turnover, and in their search for employment. While I am inclined to think that stress on a dual world of "good" and "bad" jobs is a serious oversimplification, Perry's work certainly poses a challenge to devise policies and programs that will effectively reach the structural problems that account for the glaring differences in people's work and unemployment experiences.

Hyman Kaitz: My comments touch on three areas. One topic is the pattern of unemployment flows, the second is the regression equation, and the third concerns the gross change data that enter into the last part of the paper.

One of the basic obstacles to the work I have done concerns the data available on unemployment. There is a limited amount of information on single weeks of duration, classified by sex and race. For the data that exist, the patterns for the first four weeks are apparently wrong. In my original paper I devised a method of smoothing the data with which I wasn't totally pleased, but that resulted in declining continuation rates that fit the data for various intervals of spell durations. Recently I have tried something quite

1. For empirical work on search models, see C. Duncan MacRae and Stuart O. Schweitzer, "The Relation between Vacancies and Unemployment," Urban Institute Working Paper 350-42 (November 1972). 
different by assuming that the continuation rates in the first three weeks are constant. I have also taken account of the fact that the respondent in the employment surveys rounds his answer to the nearest week of unemployment about which he is asked; and he does this with respect to the time that the interview is taken rather than with respect to the survey week, which is the previous week. Using this approach, in an equation with aggregate unemployment data, I have estimated that the continuation parameter for those first three weeks was close to, but not identical with, the figures derived in my earlier work. I am now developing a new series of completed spells and also average lengths of completed spells from the middle of 1967 to the middle of 1972 .

There still remains a basic problem about data stemming from the fact that respondents tend to round their answers in months, creating clusters of answers in the categories of four, eight, thirteen, twenty-six, and fifty-two weeks. The data must be smoothed in some manner to eliminate this clustering. If this problem can be resolved, I intend to extend the analysis into years prior to 1967 , so at the aggregate level I can examine the same relationships that Perry has derived in his study.

Concerning my second comment, there is no question that the original regression equation I reported was inadequate and yielded results that were surprising but not correct. If the equation is reestimated in logarithmic form, much better and more sensible results are obtained. In Perry's table, one finds a dummy variable used for the period since January 1967. In the original data that I used, I had annual averages for only three years after 1966 , so I did not bother to introduce a dummy term. But if monthly data through 1971 are used, clearly, a dummy should be introduced, especially because the change in the survey questionnaire was designed to have its greatest effect on teenage employment statistics. Perry also uses seasonal dummies. Here I would suggest the use of a separate set of seasonal dummies from 1967 on, because the seasonal pattern also changes, even though there would be an additional loss of degrees of freedom.

My last remark concerns Perry's use of gross change data. In connection with these, information on errors in the interview data is instructive. A small fraction of the monthly sample has regularly been reinterviewed within a short time after the original interview in order to discover whether any interviewer is not doing a good job. In the process, gross error tables have been developed that show the labor force classification at the time of the initial interview against that at the time of the reinterview. If one as- 
sumes the independence between response errors and gross changes, it is possible to derive a gross change table that is corrected for gross errors.

When I did this originally I was working with a very simple three-bythree matrix, containing the numbers of employed, unemployed, and not in the labor force. At that time, I found that errors of classification were suggesting more mobility and transition among these conditions than really took place. I analyzed only aggregate unemployment, and did not examine teenage unemployment; in the aggregate the number of people who remained unemployed from one month to the next appeared to be about 5 percent too low in the gross change data. I would guess that most of this error was concentrated among particular groups in the population. For adult males, I would expect the data to be quite accurate, since their labor force status is less ambiguous than that of other workers. When this 5 percent is allocated among those groups most affected, we would probably find a larger proportion of misclassification among younger people. This is a problem that should be studied more thoroughly, and incorporated into analysis of the sort Perry did.

George Perry: Charles Holt's suggestion for refining the calculation of continuation rates is interesting. In working with a model that allows for continual, gradual change in continuation rates over a spell, one runs into the problem that variable $p$ 's do not yield manageable expressions like his equation (2). Holt gets around this ingeniously by letting the time index, $T$, do the varying, and thus gets an integrable form he can work with to relate unemployment of different durations to continuation rates. If I had thought of this device, I would have tried to use it.

I would point out that many difficulties start where his sketch of a model ends. Most important, one would have to get around the fact that one month's distribution of unemployment by duration results from a long history of changing labor markets and hence changing continuation rates. My method dealt with this by using the fact that most of this month's unemployment is given from last month's. This month's continuation rates were then estimated from the fraction of persons leaving unemployment this month. I believe something like this would have to be worked out for Holt's model and it would lead to messy expressions for calculating monthly $p$ 's. Another practical difficulty is that a lot of data are needed. Each estimate of $p$ and $k$ pairs would require data on the number of unemployed by duration in each of three duration intervals as well as total unemployment. For my 
simplification, I needed data on one duration interval — unemployment less than five weeks.

I like the idea of exploring this problem further and I believe that allowing for gradual changes in continuation rates over the length of a spell, as Holt has done, is the most promising modification. Not only would this offer a check on the estimates made here, but it could give better information about the distribution of spell durations around the mean duration. However, I would stress that the questions dealt with in this paper did not require knowledge of how continuation rates vary over the whole length of an unemployment spell. If the average continuation rate is known, the frequency of spells, and hence the average duration of spells, can be calculated as I have done without further knowledge of the full distribution of spell lengths around that average.

Robert Hall would like me to be more cautious in interpreting my evidence from gross change data on the nature of turnover unemployment among young people. I sympathize with him to the extent that I would like readers' to be as cautious as I tried to be in presenting the evidence. For instance, the effect of school enrollment raises many more issues than I have tackled here. On a couple of points, however, Hall seems unduly cautious.

On the question of what lies behind labor force dropouts, all I would claim is that the presence or lack of job opportunities does have a lot to do with a person's decision to drop out. This result stands out quite clearly for adults as well as teenagers, groups for which reporting error is not likely to be such a large problem. Reporting error-or reporting inconsistency, to be more precise-can still mislead us; but the probabilities of dropping out are so much greater for the unemployed than for the employed that the difference cannot reasonably be attributed to reporting error. Given the result for older groups, why should I not believe that the same forces are at work for teenagers, despite the problems of response error? Finally, Hall is right to point out that there is more than one way to decompose the unemployment differentials among groups. It seemed to me most natural to treat adult males as a "best practice" control group and calculate what it would mean for other groups to take on their characteristics, one at a time. But even on Hall's reverse calculation, differences in unemployment rates for nonentrants loom large enough to establish that the unemployment differentials are not merely a problem of frequent entry. Furthermore, since entry is, in part, the other side of dropping out, and the latter is stimulated by poor employment opportunities, the high entry rates are partly a reflection of the 
poor job market these workers face rather than simply a purely voluntary norm of their behavior patterns. That kind of result is all I wanted to establish here.

\section{General Discussion}

Alan Greenspan found that the paper added significantly to our insight into the unemployment "flow" process. He noted that lack of information about the link between job creation and deletion, on the one hand, and the flow in and out of the stock of unemployment, on the other, is one of the significant deficiencies in our employment statistics. And while a broad range of flows are conceptually consistent with the published stock data, he found Perry's particular constraints a most reasonable way to achieve a unique solution.

Some participants discussed the concept of "voluntary" dropouts from the work force that Perry had tried to evaluate. William Nordhaus pointed out that the opportunity cost of not being in the work force was obviously greater for the employed than for the unemployed; this discrepancy would make Perry's probabilities different but did not correspond clearly to a voluntary versus involuntary distinction. Arthur Okun responded by emphasizing the importance of the degree of attachment to the labor force. While virtually all withdrawals are, in a sense, voluntary, a person who left the work force to go fishing while holding a job could be considered more casually attached than an unemployed person who decided to go fishing after some period of job search. Perry agreed that no simple categorization of voluntary or involuntary withdrawals could be made. But if a "purely voluntary" withdrawal were thought of as one that was not influenced by job availability, his test rejected the hypothesis that dropouts were purely voluntary. Alternatively, this simply means that job opportunities are an important determinant of dropouts. That they are also a determinant of opportunity cost does not alter this conclusion.

Nordhaus suggested that separations from the employed pool could be decomposed into quits and layoffs as a way of determining whether higher turnover resulted from voluntary or involuntary separations. If workers have increased their separations for voluntary reasons, quits as a function of unemployment should grow over time; on the other hand, if involuntary separations have risen, layoffs as a function of unemployment should have 
grown. Okun noted that quit and layoff data are available only for manufacturing, which is dominated by adult male workers to a greater degree than total employment, and therefore throw little light on the behavior of secondary workers. Thus, the data needed to check Nordhaus' interesting proposal for those parts of the work force where increased transitions have been observed are not available.

Nordhaus also reported seeing some analysis of British data that showed that continuation rates were constant over the entire length of unemployment spells. He conjectured that the increasing continuation rates found in U.S. data might be due entirely to changing average probabilities of leaving the work force as the duration of spells lengthened. Under this hypothesis, workers with longer spells would be those who were least likely to drop out in any week.

Okun expressed concern that adult males were used frequently as a fixed point of comparison. He questioned whether a 2.7 percent unemployment rate for adult males, for example, means today what it did fifteen years ago. Several factors, such as advances in educational attainment, could change the meaning of such identical unemployment figures over time. He also felt that we should analyze labor market changes as a continuous spectrum of relative shifts among all the age groups that Perry reported rather than making teenage versus adult comparisons only. He emphasized that the changes over time in unemployment experience reported in Table 4 showed a continuous variation throughout the age ranges shown, even between the younger and older halves of the 25-to-64 groups.

William Poole commented on the implications of Perry's analysis for cyclical unemployment. Since the conventional view toward unemployment maintains that longer durations normally account for most of the increases in unemployment, he found Perry's conclusion to the contrary quite interesting; for, under the conventional view, the burden of unemployment falls mostly on a few persons who must endure longer unemployment spells. Poole felt that this situation imposed a greater social cost than the situation implied by Perry, in which increases in unemployment are due mainly to a greater number of spells. Perry cautioned that even the extent of lengthening duration he calculates results in very large increases in the amount of long-term unemployment-for instance, nearly a doubling of unemployment longer than fifteen weeks between 1969 and 1971 labor market conditions.

In a final note, R. J. Gordon pointed out an additional implication of 
Perry's data on the percentage of unemployed in various age-sex groups who exit from the labor force in a given month. From these exit rates it is possible to calculate the total number of individuals who will eventually leave the labor force as the result of a permanent increase in unemployment of a given amount. Gordon presented the rough calculation from Perry's data that a permanent rise in unemployment from 4 million to 6 million would generate an additional 1 million of disguised unemployment, which is consistent with the prediction of time series labor force participation equations. He suggested that Perry might use his data to refine and extend this kind of calculation. 